\title{
Design Framework of a Stand-Alone Microgrid Considering Power System Performance and Economic Efficiency
}

\author{
Hak-Ju Lee ${ }^{1}$, Ba Hau Vu ${ }^{2}$, Rehman Zafar ${ }^{2}$, Sung-Wook Hwang ${ }^{1}$ and Il-Yop Chung ${ }^{2, *(D)}$ \\ 1 Korea Electric Power Research Institute (KEPRI), 105 Munji-ro, Yuseong-gu, Daejeon 34056, Korea; \\ jureeya@kepco.co.kr (H.-J.L.); sungwook.hwang@kepco.co.kr (S.-W.H.) \\ 2 School of Electrical Engineering, Kookmin University, 861-1, Jeongneung-dong, Seongbuk-gu, \\ Seoul 02707, Korea; vubahau@kookmin.ac.kr (B.H.V.); rehmanzafar@kookmin.ac.kr (R.Z.) \\ * Correspondence: chung@kookmin.ac.kr; Tel.: +82-2-910-4702; Fax: +82-2-910-4449
}

check for

updates

Citation: Lee, H.-J.; Vu, B.H.; Zafar, R.; Hwang, S.-W.; Chung, I.-Y. Design Framework of a Stand-Alone

Microgrid Considering Power System Performance and Economic Efficiency. Energies 2021, 14, 457. https:// doi.org/10.3390/en14020457

Received: 7 December 2020

Accepted: 12 January 2021

Published: 15 January 2021

Publisher's Note: MDPI stays neutral with regard to jurisdictional claims in published maps and institutional affiliations.

Copyright: (c) 2021 by the authors. Licensee MDPI, Basel, Switzerland. This article is an open access article distributed under the terms and conditions of the Creative Commons Attribution (CC BY) license (https:/ / creativecommons.org/licenses/by/ $4.0 /)$.

\begin{abstract}
Stand-alone microgrids integrating renewable energy sources have emerged as an efficient energy solution for electrifying isolated sites, such as islands and remote areas. The design of a microgrid involves various influential factors, including technological development, economic feasibility, and environmental impacts, based on the conditions and regulations of a particular site. This paper proposes a comprehensive microgrid design framework based on power system analysis and techno-economic analysis. The obtained optimal microgrid configuration satisfies both the design objective and power system performance regulations. The proposed design approach focuses on using practical data and can adapt to any microgrid design problems based on the local characteristics of a specific site. The practicality and effectiveness of the design framework are validated by applying it to the design of a stand-alone microgrid for Deokjeok Island in South Korea. The case study results justify the importance of considering site-specific characteristics and the impacts of power system conditions on the optimal microgrid design.
\end{abstract}

Keywords: microgrid design; stand-alone microgrid; renewable energy integration; dynamic performance; techno-economic analysis

\section{Introduction}

Electricity demands have increased exponentially in recent decades, resulting in technical and economic challenges for conventional power grids in supplying higher demands reliably. Both the industrial and academic sectors have studied alternatives to strengthen the power grids rather than the system enlargement solution with conventional energy sources, which adversely impacts the environment. Recently, there has been a paradigm shift in electric power system design from the conventional centralized systems toward decentralized and independent systems referred to as microgrids. A microgrid is defined as a group of interconnected loads and distributed energy resources (DERs) within clearly defined electrical boundaries that functions as a single controllable entity with respect to the grid [1]. A microgrid can be interconnected with the grid to operate in grid-connected mode or disconnected from the grid to operate independently in standalone mode. Grid-connected microgrids are an effective countermeasure to support the power grid by directly handling local loads and supplying ancillary services to the bulk system [1]. Furthermore, stand-alone microgrids with the integration of renewable energy sources (RESs) have emerged as the most efficient energy solution to electrify remote sites where expanding the utility grid is not economically feasible $[2,3]$.

Comprehensive literature reviews of microgrid concepts, technologies, key drivers, solid advantages, and challenges can be found in [4,5]. The outstanding advantages of microgrids include high energy sustainability, improved energy reliability and resilience, as well as better long-term cost predictability [6]. Microgrids have been considered as one of the most effective and sustainable approaches to increase renewable energy penetration 
level to reduce carbon emission [6]. The studies presented in [7,8] clarified the energy reliability, economic, and environmental benefits of microgrids with renewable energy integration. The analysis results indicated the effectiveness of microgrid deployment in reducing the system lifecycle cost, cost of energy, and emission cost. In addition to substantial energy savings, a grid-connected microgrid can enhance the energy resilience of a community under the upstream network failures [9].

Due to technological innovations, the costs of renewables and energy storage technologies have been significantly reduced $[10,11]$. This greatly enhances the practical feasibility of microgrid solutions. Especially, energy storage systems (ESSs) play a key role to enhance renewable energy integration in microgrid design and operation [12]. Due to highly flexible controllability, ESSs can be used in various applications, from short-term applications such as voltage and frequency regulation, ramp rate control, and stability improvement, to long-term ones such as peak shaving, energy arbitrage, and load leveling [12,13].

The design of microgrids can differ from case to case depending on the design objective, whether maximizing the revenues generated by a microgrid, maximizing the renewable energy penetration level, minimizing the total system operating cost, or minimizing emissions [14-16]. Furthermore, the microgrid design is associated with various influential factors, including technology availability, economic feasibility, and environmental impacts based on the conditions and regulations of a particular site. The optimal microgrid design involves determining the optimal sizing of selected DER technologies to satisfy a design objective subject to design and system operating constraints. In the literature, numerous studies have been conducted on microgrid planning and design methods using different approaches.

Several microgrid design frameworks based on techno-economic analysis were proposed. A microgrid design process considering both before-tax and after-tax cash flow analysis using the Microgrid Decision Support Tool (MDSTool) was proposed in [17,18]. The advantage of MDSTool over other commercial tools is its ability to incorporate any type of financial incentives and credits for various DER technologies in cash flow calculations for a microgrid project $[17,18]$. An optimization-based design framework for microgrids was presented in [19] that considers optimization tasks for both system configurations and operation signals for the operating cost minimization. A planning and design framework for AC-DC bi-layer microgrids was introduced in [20]. The framework is capable of determining the optimal network configuration, with both AC and DC connections, to minimize the total system cost [20].

In addition to the microgrid design approaches for economic efficiency evaluation, there are design methods proposed to consider other influential factors, such as social and environmental impacts, on the optimal design. A microgrid design framework using social, economic, and technical analysis was presented in [21]. In addition to the techno-economic analysis using the Hybrid Optimization of Multiple Energy Resources (HOMER) software, the proposed method incorporates socio-economic analysis, which evaluates the impacts of the local site's social characteristics on the optimal microgrid configuration [21]. In Ref. [22], a novel methodological framework for the design of rural microgrids was proposed. The framework comprises four stages: Selection of energy alternatives, load growth projection, techno-financial analysis, and decision analysis [22]. The advantage of the approach is its ability to consider various criteria, such as social and environmental impacts and future load growth, for selecting the optimal microgrid design. In Ref. [23], an optimal microgrid design method was presented with multiple objectives, including minimization of system operating cost, maximization of RES penetration, and minimization of pollutant emissions. Similarly, the studies presented in [24,25] discussed microgrid design methods based on techno-economic analysis considering environmental emission objectives and constraints.

There are many studies focusing on enhancements of the microgrid operation optimization technique in techno-economic analysis to obtain better microgrid design solutions. In Ref. [26], the authors presented a method for the optimal sizing of power generation units in a microgrid using a particle swarm optimization (PSO) algorithm. The optimal microgrid 
configuration was determined based on the least-cost perspective approach [26]. Similarly, the studies presented in [27-29] proposed methodologies to determine the optimal sizing of stand-alone systems to minimize the total system cost, and the optimization problem was solved by genetic algorithms (GA). The application of a grasshopper optimization algorithm, which is the latest metaheuristic optimization technique, in the optimal microgrid design problem was discussed in [30]. The optimal sizing of DER technologies was determined to minimize the system cost of energy (COE) considering a microgrid reliability constraint, which is the deficiency of power supply probability [30]. The research presented in [31] proposed a novel hybrid techno-economic optimization method for distributed energy systems and microgrids design. The method has advantages for the optimal design of grid-connected microgrids with islanded operating conditions [31].

These microgrid design methods are fundamentally based on the techno-economic analysis with some modifications to integrate new parameters. However, most of the design approaches in the literature do not consider the impacts of existing power system conditions at the site. This is a crucial consideration, especially for the design of standalone microgrids with a high penetration of renewable energy. Stand-alone microgrids designed for islands or remote areas are typically based on the current power systems at the locations, which are usually powered by internal combustion engine generators. Furthermore, off-grid hybrid renewable energy systems are represented by their low system inertia, making the system frequency vulnerable to instantaneous power imbalances caused by RES output intermittency [32]. This is a technically unique and challenging feature of stand-alone microgrids compared to grid-connected systems. For these reasons, besides the indispensable techno-economic analysis, it is essential to perform the power system analysis for microgrid planning and design procedures.

Noting the above-mentioned gap, this study proposes a comprehensive microgrid design framework incorporating power system analysis and techno-economic analysis. Based on the current power system and microgrid design specifications, the power system analysis is performed to determine the technical design and operating constraints to satisfy power system performance regulations. The identified constraints and other input data are applied in the techno-economic analysis to find the optimal microgrid configuration. Accordingly, the optimal design obtained by the proposed methodology satisfies both the design objective and technical constraints to ensure high power system performance.

The major advantage of the proposed approach is that it dramatically improves the realistic feasibility of a microgrid design solution. The practicality and effectiveness of the proposed microgrid design framework are validated by applying for a real stand-alone microgrid design for Deokjeok Island in Gyeonggi-do, South Korea, which is located approximately a $3 \mathrm{~h}$ drive from Seoul. In this case study, the power system analysis is performed using PowerFactory software (Version 2017 SP4, Gomaringen, Germany) while the techno-economic analysis is conducted in the HOMER tool. The optimal design aims to maximize the system economic efficiency with renewable energy integration, while ensuring high power system performance. The analysis results justify the significance of considering site-specific characteristics in the design process and the impacts of power system enhancements on the optimal microgrid configuration.

The remainder of this paper is organized as follows. Section 2 presents the proposed microgrid design framework. Section 3 describes the power system configuration of Deokjeok Island. The power system analysis and techno-economic analysis for the Deokjeok Island microgrid design are presented in Sections 4 and 5, respectively. Section 6 discusses the impacts of power system improvements on the optimal microgrid design, and the conclusions are provided in Section 7.

\section{Proposed Microgrid Design Framework}

A complete microgrid design involves the design of the electrical network structure, power system control and operation, and the optimal selection of DERs subject to a specific objective considering local conditions of the site such as existing power system facili- 
ties, power system performance regulations, available technologies, energy demand and consumption status, available energy resources, and local economy and policies. The motivation of this study is to propose a design framework for stand-alone microgrids with high renewable energy penetration based on power system performance and techno-economic feasibility, thereby providing microgrid designers a methodology to evaluate the system's dynamic and steady-state performance, energy reliability, and economic efficiency.

Figure 1 presents the proposed microgrid design framework, which can be divided into three major sections: Power system analysis, techno-economic analysis, and optimal sizing and configuration design. The objective of power system analysis is to identify the technical operating constraints under which the power system performance is guaranteed. Subsequently, these are considered as hard constraints applied in the techno-economic analysis to obtain feasible microgrid configurations, which mean sizing options of DERs. As a result, the optimal microgrid design is selected among feasible configurations.

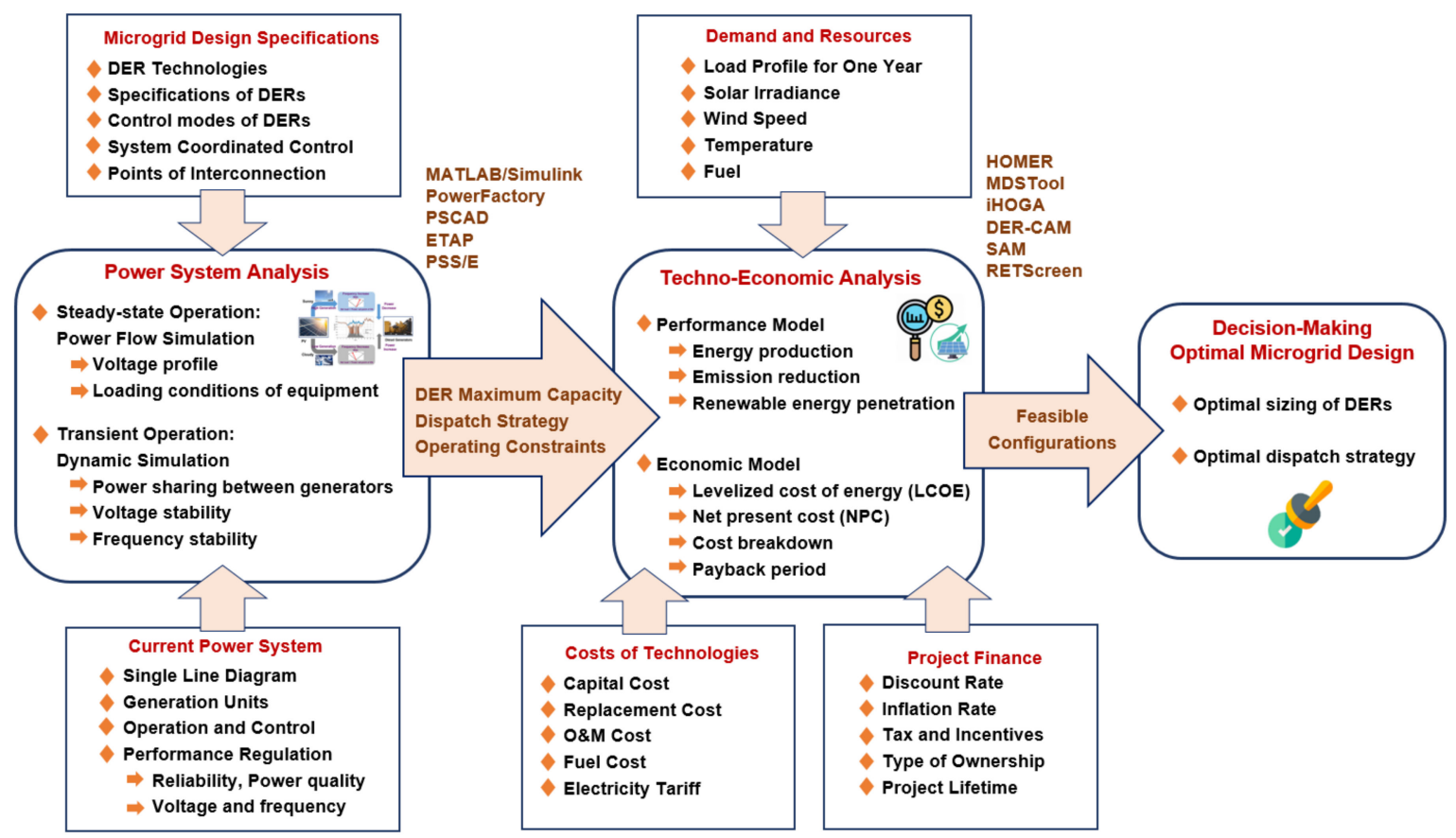

Figure 1. Proposed microgrid design framework.

Compared to other microgrid design procedures mentioned in [17-25], the primary advantage of the proposed framework is that the optimal microgrid design satisfies both the design objective and the operating constraints, ensuring high power system performance. In practice, the power system performance requirements vary from system to system, and from region to region. The fundamental techno-economic analysis solely determines the optimal capacity of DERs by solving a power balance optimization problem without considering essential technical performance measures of a microgrid, such as voltage and frequency regulations. For these reasons, the proposed framework enhances the realistic feasibility of a microgrid design solution for a specific site. Furthermore, this design process provides a method to analyze the impacts of power system improvements on the optimal microgrid configuration. Therefore, the most technically and economically feasible design solution can be obtained based on site-specific characteristics.

The technical problems of RES integration include over-voltage due to reverse power flow and transient instability due to abrupt changes in RES output power. These critical performance issues are addressed in power system analysis using power flow analysis and dynamic simulation. The input data required for power system analysis include the single line diagram, equipment data, operation and control schemes, and regulations. The single 
line diagram contains the power network configurations and information about power equipment including generators, transformers, and loads, protective switches, and so on. The system operation and control methods are essential to evaluate the performance of the current power system, which directly affects how new generation units can be integrated into the system. The performance regulations, including reliability, power quality, and voltage and frequency regulations, facilitate analyzing the impacts of RES integration.

In addition, the technical specifications of the designed microgrid are required to evaluate the system performance under a high penetration level of renewable energy. The data include the selected DER technologies and their specifications, control modes of individual DERs and the system coordinated control schemes, and points of interconnection at which DERs are electrically interconnected to the power system. These design parameters strongly affect the optimal microgrid configuration. For instance, a simple coordinated control scheme may be adopted for a stand-alone microgrid designed for an isolated and remote site, where advanced technologies are limited and conducting maintenance activities is problematic. Consequently, the integrated RES capacity is limited to guarantee the system reliability. On the other hand, state-of-the-art control algorithms supported by fast and reliable communication technologies can be deployed in developed areas, resulting in a higher RES hosting capacity.

Based on these data, the power system analysis is conducted to evaluate the technical performance of microgrid under the designed specifications considering worst-case scenarios and contingency analysis. The power flow analysis uses standard models and solutions while the dynamic models of DERs used for transient simulation may vary depending on their specifications and control modes. Accordingly, user-defined DER dynamic models are developed by researchers to satisfy the accuracy requirements of dynamic simulation. There are many power system analysis tools for academic studies and industrial operations. The most widely used tools are MATLAB/Simulink [33], PowerFactory [34], PSCAD [35], ETAP [36], and PSS/E [37]. These tools offer users significant flexibility to build dynamic models for specific plants and controllers. As described above, this step decides the design constraints to ensure the system stability and reliability, such as the maximum capacity of DERs, energy dispatch strategy, and other operating constraints.

The technical constraints determined by the power system analysis, together with demand and resources data, costs of DERs, and project financial parameters, are the input of techno-economic analysis, which aims to determine the optimal microgrid configuration considering all the costs and economic benefits by operating a microgrid over its lifetime. The techno-economic analysis typically consists of two computation models, which are the performance model and economic model. Based on the input data of energy demand profile, generation capacity, dispatch strategy, and operating constraints, the performance model simulates the power balance operation of a microgrid for a complete year and records all relevant variables, including the energy production profile and operating states of generation units.

Subsequently, the economic model uses these data to calculate all the costs and benefits associated with the system operation over its lifetime, which are used to compute economic measures for the system's economic efficiency evaluation. The techno-economic analysis generates all feasible configurations that satisfy the design constraints, with their corresponding economic metrics and detailed system operation profiles. At present, the popular tools for techno-economic analysis of a power system with DERs integration are HOMER [38], MDSTool [18], iHOGA [39], DER-CAM [40], SAM [41], and RETScreen [42]. Finally, the optimal microgrid configuration is selected among the feasible configurations based on the design objective.

The proposed microgrid design framework focuses on practical considerations for a specific microgrid at a specific site. It is apparent that the optimal microgrid configurations differ for different areas, depending on many particular properties such as geographical conditions, local economy, available technologies, operation and maintenance conditions, and availability of well-trained system operators. Therefore, this process increases the 
realistic feasibility of a microgrid design solution. Furthermore, this method enables the designer to examine the impacts of different design specifications on the optimal solution, such as the impacts of coordinated control schemes on the system economic efficiency. Therefore, the designer can select the most suitable specification for a particular microgrid. The proposed microgrid design approach is applied to design a real stand-alone microgrid for Deokjeok Island in South Korea as a case study to justify its effectiveness. The design objective is to maximize the system economic efficiency with high renewable energy penetration while guaranteeing high power system performance.

\section{Power System Configuration of Deokjeok Island}

\subsection{Current Power System Configuration}

Deokjeok Island has an area of $20.87 \mathrm{~km}^{2}$ with a current population of 1947 people living in 1072 households. The estimated maximum, average, and minimum loads are 1900, 1190 , and $700 \mathrm{~kW}$ respectively. The average energy consumption demand of the island is $28,554 \mathrm{kWh} /$ day. Based on an on-site study, a single line diagram of the existing power system was constructed, as illustrated in Figure 2.

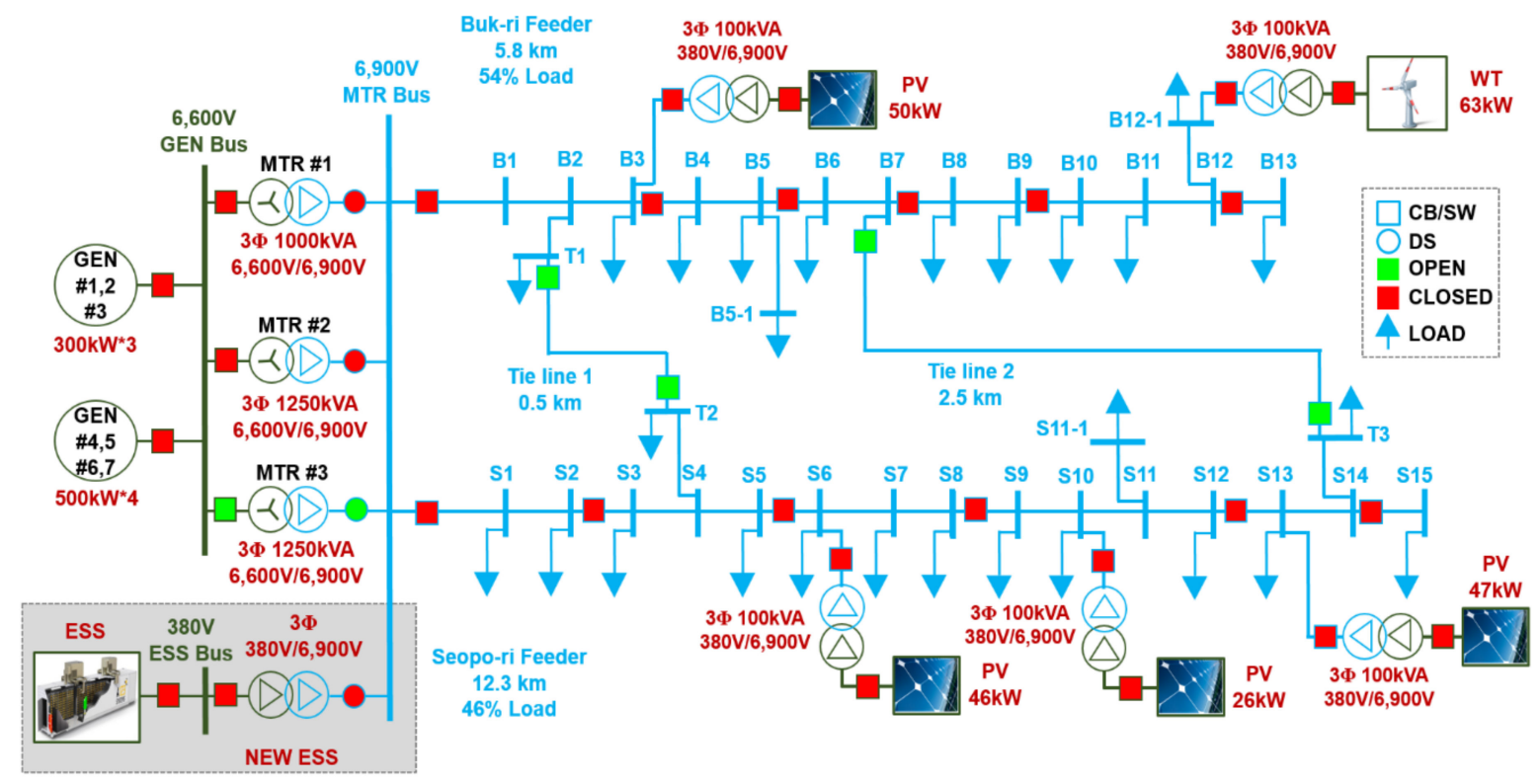

Figure 2. Single line diagram of the current power system of Deokjeok Island.

Currently, Deokjeok Island is powered by diesel generators, photovoltaic (PV) systems, and wind turbine (WT) generators. It should be noted that the ESS in Figure 2 is not installed yet, and it only indicates how the ESS will be interconnected with the system for the designed microgrid configuration. The diesel power plant has a rated generation capacity of $2900 \mathrm{~kW}$, comprising three $300 \mathrm{~kW}$ generators and four $500 \mathrm{~kW}$ generators. The total rated power of PV systems is $169 \mathrm{~kW}$, and that of WTs is $63 \mathrm{~kW}$. The wind power plant is composed of $11 \mathrm{WTs}$, each of $3 \mathrm{~kW}$; and $3 \mathrm{WTs}$, each of $10 \mathrm{~kW}$. It is seen that the total RES capacity is $232 \mathrm{~kW}$, which is only $33 \%$ of the minimum load. Therefore, the power system of Deokjeok Island has not witnessed any issues associated with RES integration.

The distribution system utilizes a medium voltage level of $6900 \mathrm{~V}$ with a $60 \mathrm{~Hz}$ nominal frequency, which is the standard distribution voltage for small and medium islands in South Korea. There are two main feeders, namely Buk-ri and Seopo-ri feeders, with two normally open tie lines between them. The type of line conductor is an aluminium conductor steel-reinforced (ACSR) $240 \mathrm{~mm}^{2} 6900 \mathrm{~V}$ overhead cable. Sectionalizing switches are installed along the two feeders to minimize the areas affected by faulted conditions. The single line diagram shows that the current power system was well designed to have high 
system reliability. This radial configuration with normally open tie lines and sectionalizing switches on main feeders is the standard design applied in South Korea.

In this system, diesel generators are the main sources that control the system voltage and frequency, and respond to instantaneous power imbalances. Parallel diesel generators are operated by droop control with 5\% frequency droop regulation. PVs and WTs are operated by maximum power point tracking (MPPT) algorithms to extract the maximum power available from solar irradiance and wind. Table 1 describes the voltage and frequency regulation for DER interconnection applied in Deokjeok Island. The clearing time is defined as the duration between the detection of an abnormal condition and the disconnection of DER units. This operating regulation will be applied for the power system analysis of the microgrid design.

Table 1. Voltage and frequency regulation for distributed energy resources (DERs) interconnection in Deokjeok Island.

\begin{tabular}{ccc}
\hline Parameter & Operating Range & Clearing Time (s) \\
\hline \multirow{4}{*}{ Voltage } & $\mathrm{V}<0.5 \mathrm{pu}$ & 0.167 \\
& $0.5 \mathrm{pu} \leq \mathrm{V}<0.9 \mathrm{pu}$ & 2 \\
& $0.9 \mathrm{pu} \leq \mathrm{V} \leq 1.1 \mathrm{pu}$ & Continuous operation \\
& $1.1 \mathrm{pu}<\mathrm{V}<1.25 \mathrm{pu}$ & 2 \\
& $1.25 \mathrm{pu} \leq \mathrm{V}$ & 0.167 \\
\hline \multirow{2}{*}{ Frequency } & $\mathrm{f}<58.5 \mathrm{~Hz}$ & 1.5 \\
& $58.5 \mathrm{~Hz} \leq \mathrm{f} \leq 61 \mathrm{~Hz}$ & Continuous operation \\
& $61 \mathrm{~Hz}<\mathrm{f}$ & 1.5 \\
\hline
\end{tabular}

\subsection{Microgrid Control Structure}

As mentioned in the proposed microgrid design process, the system control method strongly affects the power system analysis and, consequently, the optimal microgrid design. The microgrid control structure comprises the control modes of individual DERs and coordinated control schemes, which define how DERs are operated in parallel. Figure 3 presents the control concept of Deokjeok Island microgrid. In normal operating conditions, PVs and WTs are operated by MPPT algorithms to produce the maximum available power. In addition, the output power of PV systems is limited by a maximum threshold, which can be easily configured in PV inverters and does not require any additional control or communications. By contrast, in abnormal conditions such as unexpected low load or unavailability of ESSs due to maintenance operations, PV and WT systems are controlled in power reduction mode by switching off appropriate PV arrays and WTs to ensure the power balance and system reliability.

Diesel generators can be operated in droop control to maintain the system voltage and frequency, or in active power/reactive power $(\mathrm{P} / \mathrm{Q})$ control to generate the desired power setpoints issued by the central controller. Similarly, the ESS has constant voltage/constant frequency $(\mathrm{CVCF})$ control with droop settings available and $\mathrm{P} / \mathrm{Q}$ control, which are also called grid-forming and grid-parallel or grid-feeding controls in the literature, respectively $[3,43]$. In CVCF control, the ESS operates as a voltage source controlling the system voltage and frequency. If the ESS has only one converter operated in CVCF, its terminal voltage magnitude and frequency are controlled at constant values. When multiple ESS converters are operated in $\mathrm{CVCF}$, they are controlled by droop characteristics similar to conventional generators. Based on the control modes of individual DERs, there are two coordinated control schemes for Deokjeok Island microgrid, which are called diesel-on mode and diesel-off mode in this study. 


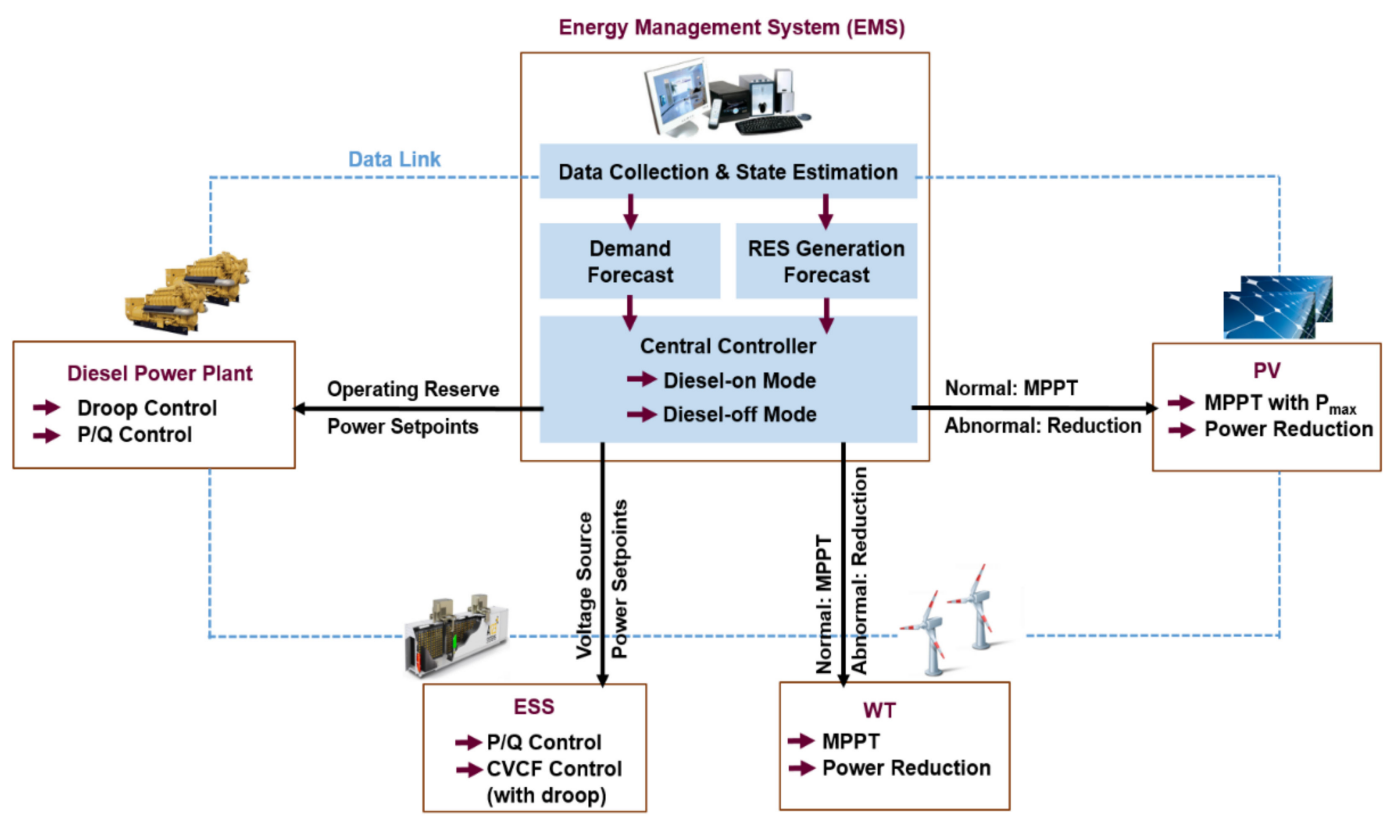

Figure 3. Microgrid control structure for Deokjeok Island.

In diesel-on mode, diesel generators are operated by droop control while the ESS is in $\mathrm{P} / \mathrm{Q}$ control. Diesel generators are the source controlling the system voltage and frequency. When RES generation is greater than the load demand, online diesel generators operate at their minimum loading condition, which is typically $25 \%$ of their rated power. Online generators mean the generators that are turned on, synchronized with the system and delivering power to the network. Any surplus power produced by RESs is used to charge the ESS.

In diesel-off mode, the ESS is operated by CVCF control as the reference source forming the microgrid voltage and frequency and responding to instantaneous power variations. The most important feature of this coordinated control scheme is that all diesel generators can be turned off entirely under the condition that the energy stored in ESSs and RES generation are sufficient to supply the entire load, which is achievable during the daytime on sunny days. Therefore, diesel-off mode maximizes renewable energy penetration and minimizes fuel consumption.

\subsection{Power System Modeling Including DER Models}

The dynamic models of DER technologies are developed based on their control features, as presented in Figure 3. The purpose of these models is to simulate and evaluate the system's dynamic performance under the coordinated control schemes, hence identifying related system operating constraints that are subsequently applied to the techno-economic analysis to find the optimal microgrid design.

\subsubsection{PV Model}

The block diagram of the PV dynamic model developed in this study is presented in Figure 4. The model consists of solar modules, a DC link capacitor, a three-phase pulsewidth modulation (PWM) inverter, and an LC filter. The model integrates the perturband-observe (P and O) MPPT algorithm [44]. PV systems operate as current sources, and $\mathrm{PV}$ inverters are controlled in $\mathrm{P} / \mathrm{Q}$ mode, referred to as grid-feeding mode and explained comprehensively in [43]. 


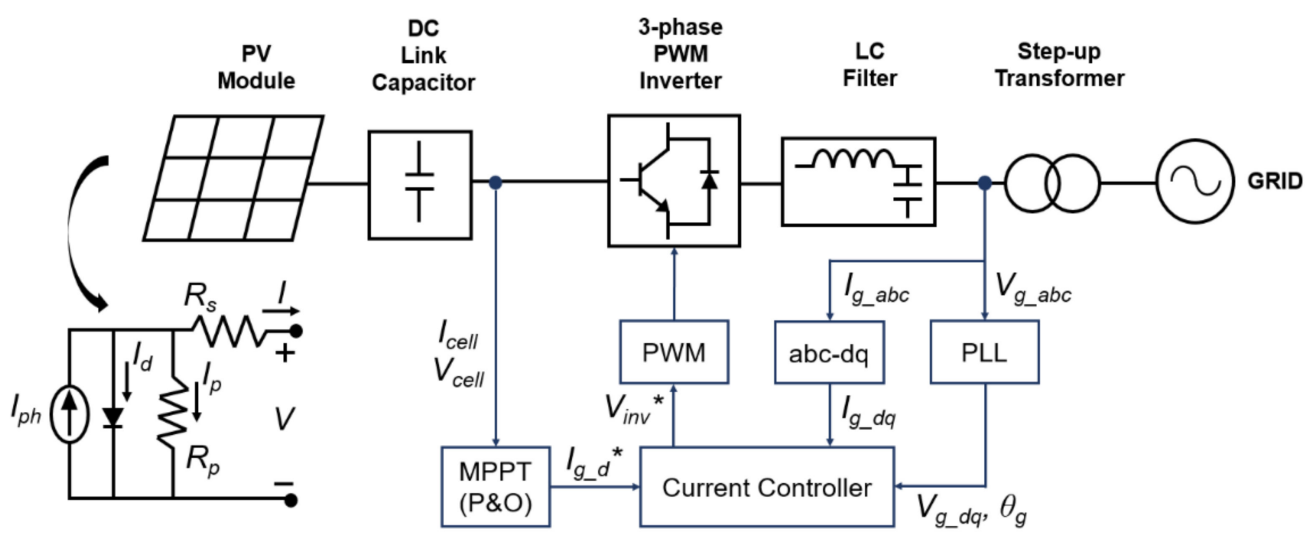

Figure 4. Simplified block diagram and control of photovoltaic (PV) system.

A single diode-equivalent circuit with series and parallel resistance is used to model the PV cell. This equivalent model is the most accurate and practical by considering series and parallel resistance to incorporate their impacts on the efficiency of the PV cell and PV module [45]. Using this model, the output current of a PV cell is calculated using the following equations $[45,46]$ :

$$
\begin{gathered}
I_{p h}=\frac{G}{G_{r e f}}\left[I_{p h, r e f}+\mu_{s c}\left(T_{\text {cell }}-T_{\text {cell }, \text { ref }}\right)\right] \\
I=I_{p h}-I_{0}\left\{\exp \left[\frac{q\left(V+I \cdot R_{s}\right)}{k T_{\text {cell }} A}\right]-1\right\}-\frac{V+I \cdot R_{s}}{R_{p}}
\end{gathered}
$$

where $I_{p h}(\mathrm{~A})$ is the photocurrent, $G\left(\mathrm{~W} / \mathrm{m}^{2}\right)$ is the currently available solar irradiation, $G_{r e f}=1000\left(\mathrm{~W} / \mathrm{m}^{2}\right)$ is the reference solar irradiation defined at standard test conditions (STC), $I_{p h, r e f}(\mathrm{~A})$ is the reference photocurrent at STC and is approximately equal to the short-circuit current of the PV cell at STC, $\mu_{s c}(\mathrm{~A} / \mathrm{K})$ is the temperature coefficient of the short-circuit current, $T_{\text {cell }}(\mathrm{K})$ is the actual cell temperature, $T_{\text {cell, ref }}=298(\mathrm{~K})$ is the cell temperature at STC, $I(\mathrm{~A})$ is the $\mathrm{PV}$ output current, $I_{0}(\mathrm{~A})$ is the reverse saturation current of the diode, $q(\mathrm{C})$ is the electron charge, $k(\mathrm{~J} / \mathrm{K})$ is the Boltzmann constant, $A$ is the ideality factor, $V(\mathrm{~V})$ is the PV output voltage, $R_{S}(\Omega)$ is the series resistance, and $R_{p}(\Omega)$ is the parallel resistance.

\subsubsection{WT Model}

The block diagram and control structure of the WT is presented in Figure 5. The dynamic model of a wind power system includes a WT, a permanent magnet synchronous generator (PMSG), and a full-scale back-to-back converter, which is composed of a machineside converter (MSC), a DC link capacitor, and a grid-side inverter (GSI) [33,47]. In this structure, the rotational speed of the PMSG is regulated by the MSC to produce the maximum power from the available wind. The GSI controls the DC link voltage and reactive output power [33]. Similarly to the PV inverter, the GSI is controlled in gridfeeding mode [43]. 


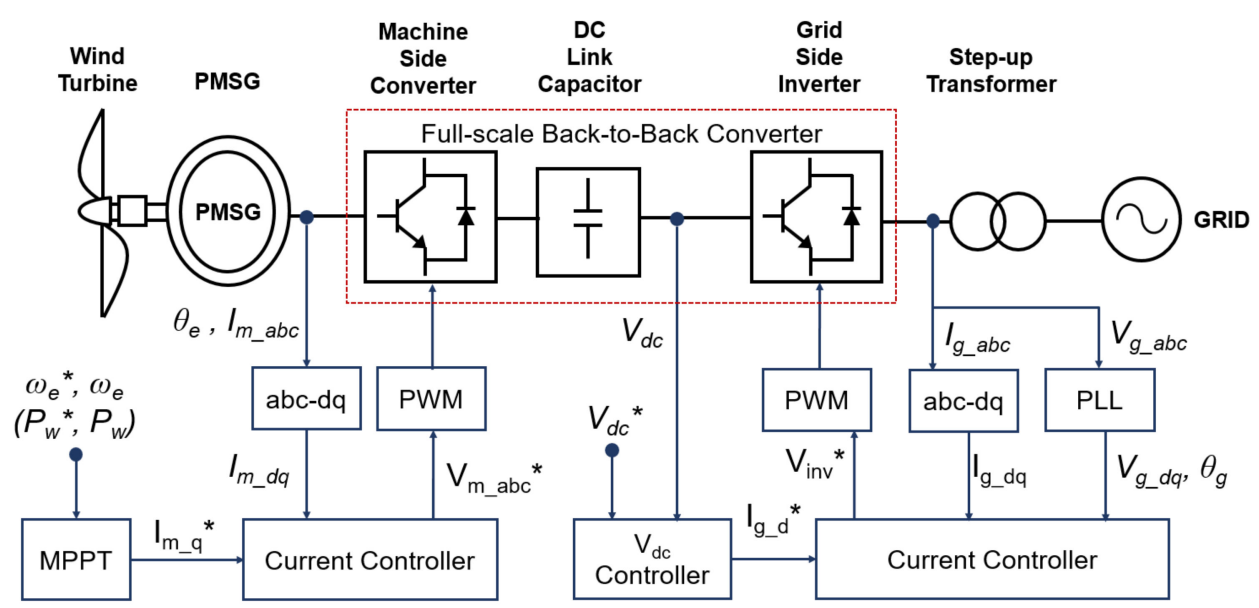

Figure 5. Simplified block diagram and control of wind turbine (WT) system.

The maximum mechanical power extracted by the WT from the available wind can be determined by the following equations [48]:

$$
\begin{gathered}
\omega_{t, o p t}=\frac{\lambda_{o p t} V_{w}}{r} \\
P_{w, \max }=\frac{1}{2} \rho \cdot \pi r^{2} \cdot C_{p, \max } \cdot\left(\frac{\omega_{t, o p t} r}{\lambda_{o p t}}\right)^{3}
\end{gathered}
$$

where $P_{w, \max }(\mathrm{W})$ is the maximum mechanical output power of the wind turbine, $\rho\left(\mathrm{kg} / \mathrm{m}^{3}\right)$ is the air density, $r(\mathrm{~m})$ is the radius of the wind turbine blade, $C_{p, \max }$ is the maximum wind turbine power coefficient, $\omega_{t, \text { opt }}(\mathrm{rad} / \mathrm{s})$ is the optimal wind turbine rotor speed, $\lambda_{\text {opt }}$ is the optimal tip-speed ratio, and $V_{w}(\mathrm{~m} / \mathrm{s})$ is the wind speed.

\subsubsection{ESS Model}

The ESS block diagram and its controllers are illustrated in Figure 6. The components of an ESS include a battery bank, a DC link capacitor, a PWM converter, and an LC filter. The control structure of the ESS converter consists of a current control loop and a voltage control loop [49]. The details of ESS current and voltage controllers can be found in [43,49].

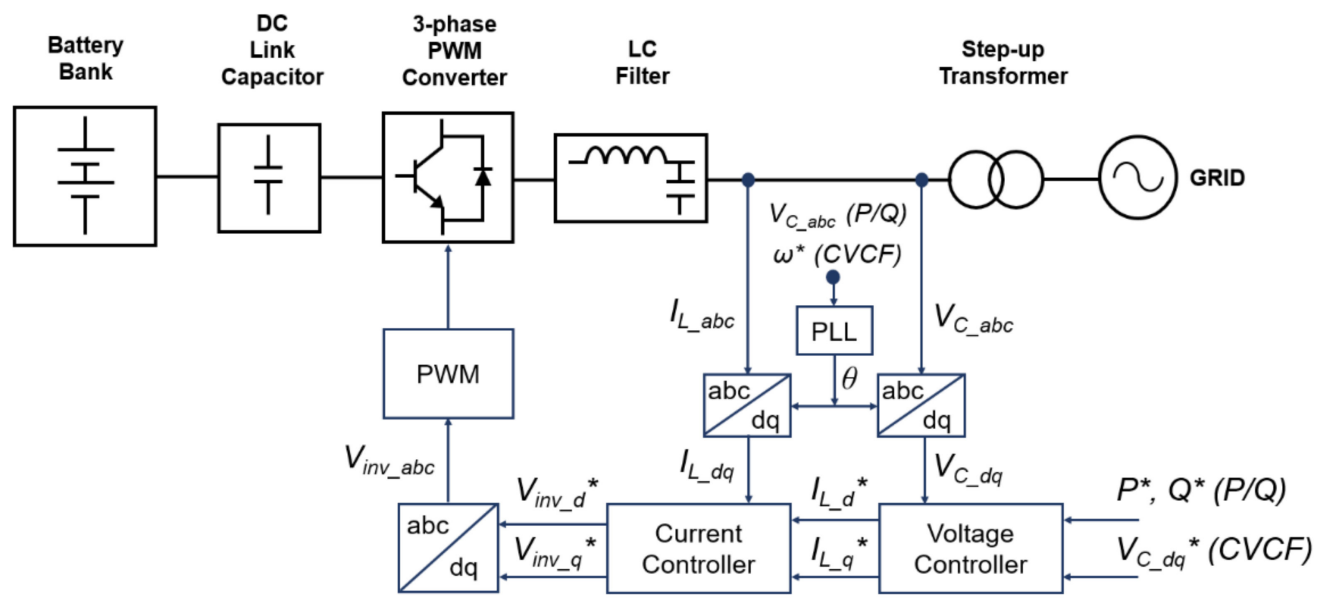

Figure 6. Simplified block diagram and control of energy storage systems (ESSs).

When the ESS operates in CVCF control, the ESS converter is controlled in a closed loop to operate as an AC voltage source with predefined setpoints of its terminal voltage 
magnitude and frequency. The voltage controller controls the ESS terminal voltage to match its reference value while the current controller regulates the ESS output current. Therefore, the controlled current flowing through the inductor instantaneously charges the capacitor to regulate the output voltage at its setpoint [43]. In this control mode, the system frequency is generated by an internal oscillator [49]. The AC voltage generated by the CVCF ESS is used as the reference for the other generation units, such as PV, WT, and diesel generators.

In $\mathrm{P} / \mathrm{Q}$ or grid-feeding control, the ESS converter is controlled as a current source to generate or absorb the desired active and reactive power values. The ESS terminal voltage is synchronized with the system voltage measured at the point of common coupling (PCC). In this control scheme, a phase-locked loop is used to detect the system frequency and the phase angle at the PCC using a synchronous reference frame transform [49].

\subsubsection{Diesel Generator Model}

The block diagrams of the diesel generator model and its governor model are presented in Figure 7. The generator model consists of four main components, which are a synchronous machine, a diesel engine, a governor, and an excitation system. The governor controls the rotational speed of the diesel engine, hence controlling the electrical frequency at a reference value under variations in electric demand [50]. The fundamental function of an excitation system is to provide and control the direct current to the synchronous machine field winding, hence controlling the output terminal voltage of the generator [50]. An excitation system normally has an automatic voltage regulator (AVR) to regulate the generator output voltage at a predefined setpoint.
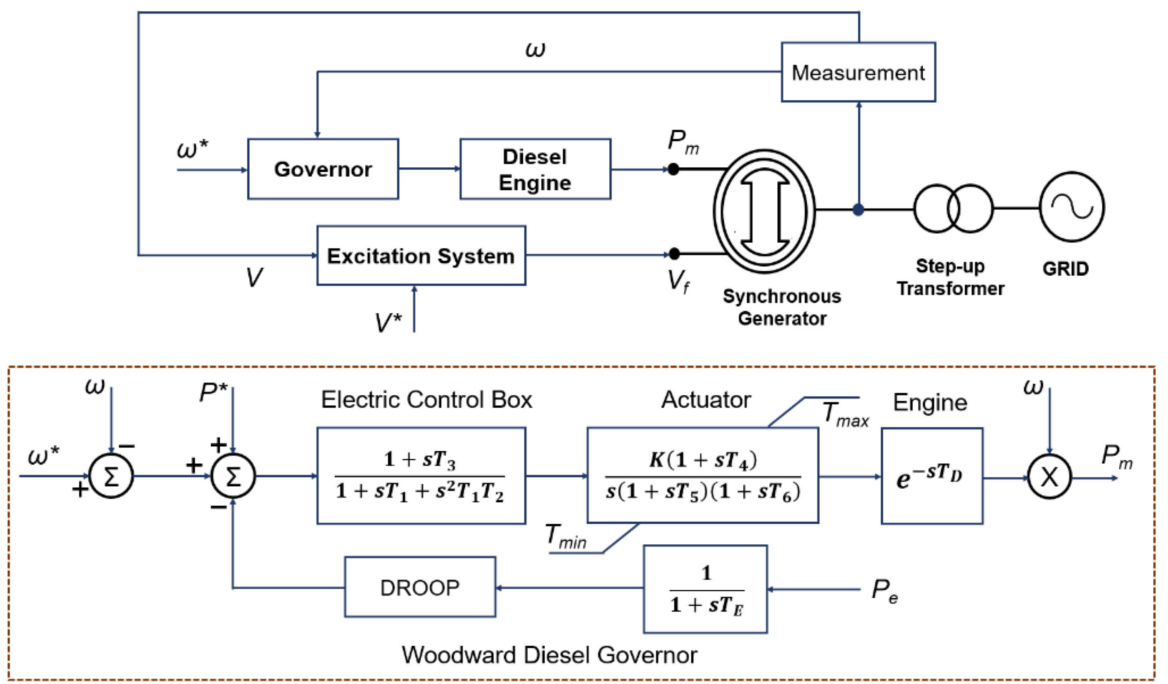

Figure 7. Simplified block diagrams of diesel generator model and its governor model.

Basically, the simulation accuracy on the dynamic response of diesel generators depends on the model implementation and parameter selection of synchronous machines and their controllers. The mathematical models of the synchronous machine, governor, and excitation system have been comprehensively and accurately developed in the literature. There are several standard models that are typically implemented in the built-in library of power system simulation tools. In this paper, the standard models provided in PowerFactory are used to simulate the dynamic performance of the diesel generator. The dynamic parameters of synchronous machine models are taken from the corresponding generator datasheets. The standard simplified excitation system is deployed [51]. For the governor model, the Woodward diesel governor is selected as this controller is used in the existing system with $5 \%$ frequency droop regulation [51]. 


\section{Power System Analysis for Microgrid Design}

This section presents the power system analysis for the design of Deokjeok Island microgrid. As presented, the current power system of the island already has some PVs and WTs. PV systems have several crucial advantages over WTs. A solar power system typically has no rotating parts, resulting in much lower operation and maintenance costs and higher durability over a wind energy system. Therefore, PVs normally have longer lifetimes than WTs. The transportation and installation of WTs are significantly more challenging than for PVs, which partially constitutes to the lower total installation cost of PVs. Moreover, WTs are more susceptible to very high winds and lightning. For these reasons, the microgrid design for Deokjeok Island considers more PV installations while the WT capacity is kept at $63 \mathrm{~kW}$.

In a diesel-based microgrid, it is obvious that ESSs must be integrated to increase the renewable energy penetration. The interconnection points of ESSs and PVs are depicted in Figure 2. New PV arrays and inverters will be installed at the existing PV sites while the ESS will be connected to the main $6900 \mathrm{~V}$ bus via an independent step-up transformer. In this study, the PowerFactory tool of DIgSILENT is selected to perform the power system analysis due to its advantages in solving power flow problems for both AC and DC systems, and for balanced and unbalanced networks [34]. In addition, PowerFactory allows the user to develop and model specific controllers and block diagrams of power plants with a great degree of freedom, which are then used for dynamic simulation [34].

\subsection{Power Flow Analysis}

The single line diagram of Deokjeok Island microgrid shown in Figure 2 is implemented in PowerFactory software for the power system analysis, as presented in Figure 8. As described previously, one of the critical issues with RES integration is over-voltage near the interconnection points. This problem can be verified by power flow analysis, and the primary interest is to check the system voltage profile.

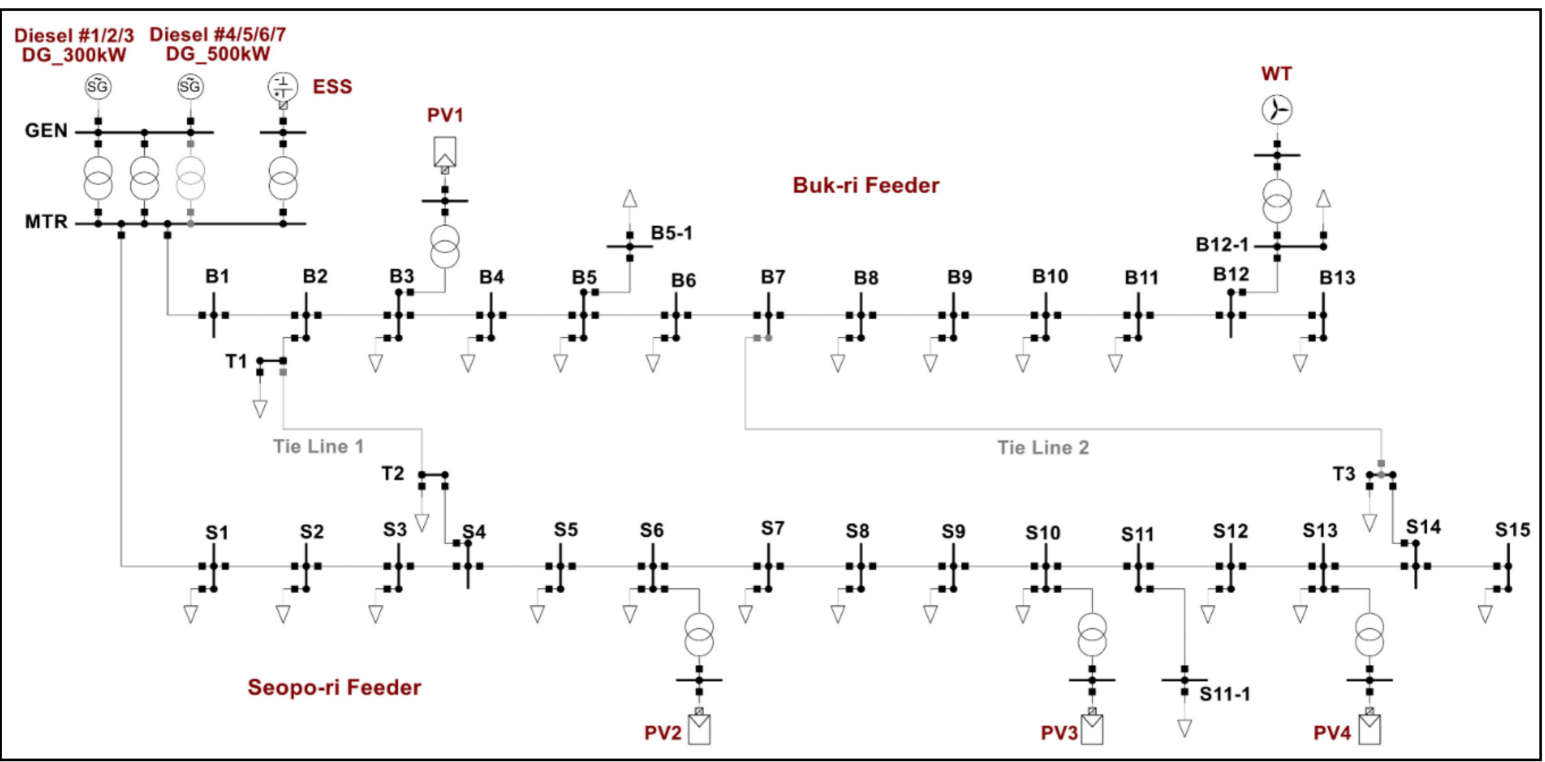

Figure 8. Deokjeok Island microgrid modeling in PowerFactory.

The fundamental cause of the over-voltage problem due to RES integration is the reserve power flow from the RESs in the network. The worst-case scenario considered for over-voltage is under the minimum load and maximum RES generation. Therefore, this scenario is selected in this study. The minimum load of this island microgrid is $700 \mathrm{~kW}$. The power flow simulation is performed considering different levels of PV generation. The results of the microgrid voltage profile are depicted in Figure 9. 

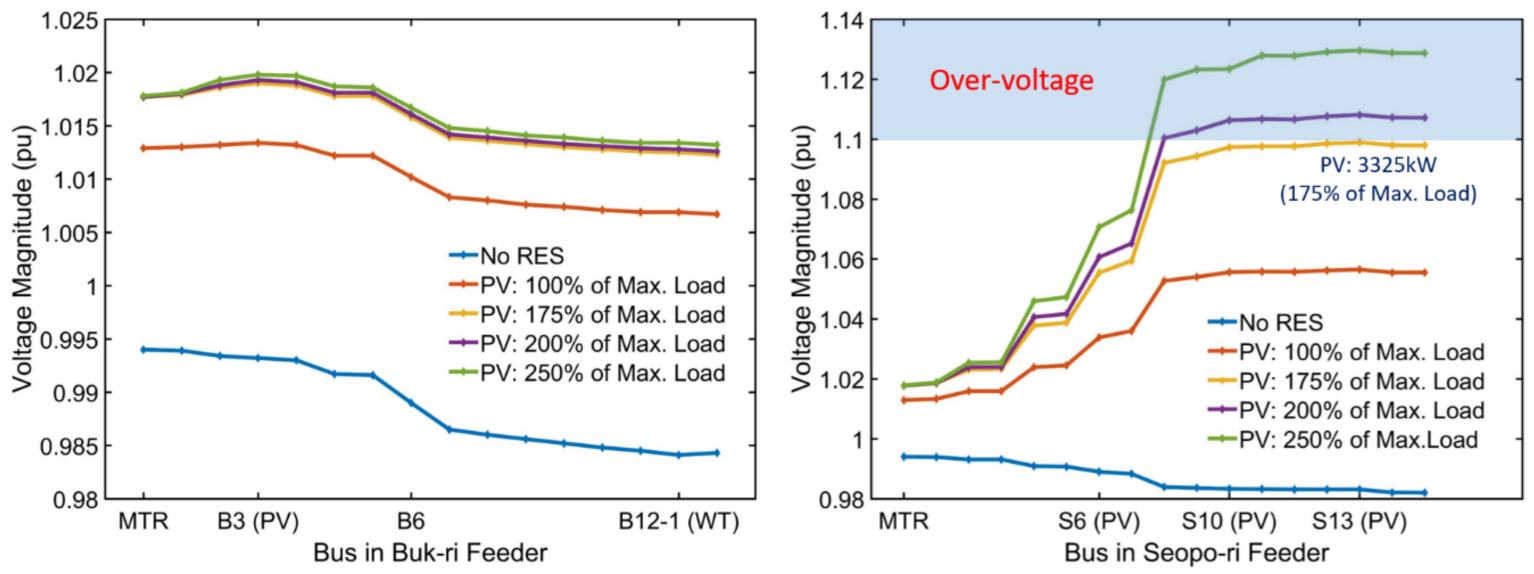

Figure 9. System voltage profile under minimum load and different PV generation levels.

Regarding the over-voltage problem, the Buk-ri feeder has a better voltage profile because this feeder is shorter and hosts only one PV plant and a small WT plant. By contrast, the Seopo-ri feeder accommodates three PV plants, resulting in larger reverse power flows. With the existing feeder configuration, the results indicate that the over-voltage problems occur in the Seopo-ri feeder when the total PV generation exceeds $3325 \mathrm{~kW}$, which is $175 \%$ of the microgrid maximum load. Therefore, the total maximum output power of the four $\mathrm{PV}$ plants is limited to $3325 \mathrm{~kW}$ for a reliable microgrid design. This constraint will be applied in the techno-economic analysis for DER sizing.

\subsection{Dynamic Simulation}

Regarding the microgrid dynamic stability, the crucial problem of RES generation is abrupt variations in their output power with significant ramp rates. These variations subsequently cause voltage and frequency deviations. In the worst case, if voltage and frequency deviate out of the regulation ranges, load shedding and RES disconnection may be triggered, and system collapse may even occur. Therefore, the primary interest of dynamic simulation in this study is the impact of severe PV output fluctuations on the microgrid stability, thereby identifying associated design constraints, which are then applied in the next step in the proposed microgrid design process.

In order to define the worst ramp-down event of PV power variations, a real-world dataset of measured PV generation was analyzed in this study. The dataset is extracted from microgrid data of a research building in Tsukuba, Japan [52]. The dataset recorded the actual output power of a $90.84 \mathrm{~kW}$ PV system starting from 1 January 2015 to 24 April 2018 [52]. With a high $1 \mathrm{~s}$ time-step resolution, this dataset conserves all essential dynamic characteristics of PV power fluctuations. Using this dataset, the ramp rates of PV power variations are computed for different time intervals, and the results are presented in Figure 10. The negative values indicate ramp-down rates while the positive values show ramp-up rates.

Apparently, the PV power ramp rates over longer time intervals are higher in both magnitude and frequency of observations. Regarding the impacts of PV power fluctuations on the microgrid dynamic performance, the ramp rates over $1 \mathrm{~s}, 10 \mathrm{~s}$, and 1 min intervals are considered because they directly affect the transient frequency variations. From the analysis, the highest ramp-down rates over $1 \mathrm{~s}, 10 \mathrm{~s}$, and 1 min intervals are $44 \%, 53 \%$, and $56 \%$, respectively. Therefore, for a conservative approach, this study considers a PV power ramp-down rate of $60 \%$ over a $1 \mathrm{~s}$ interval as the worst $\mathrm{PV}$ ramp-down event for the dynamic simulation. 

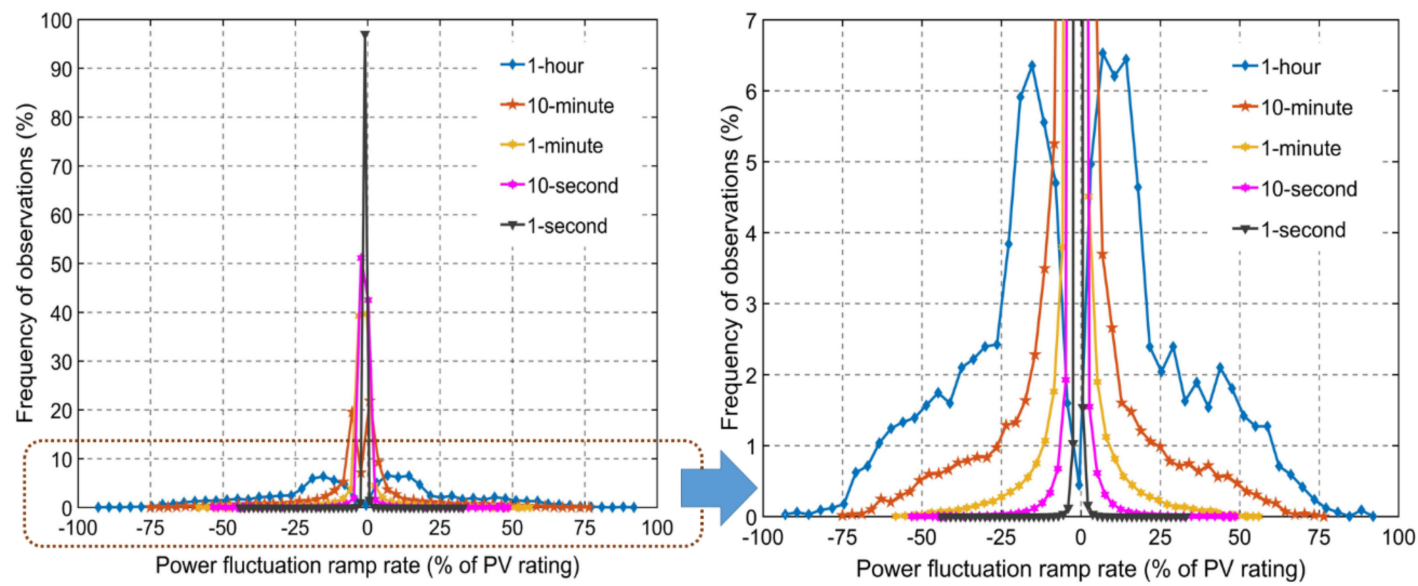

Figure 10. Extracted power ramp rates from the PV generation measurement dataset in Tsukuba, Japan.

The worst-case scenarios of microgrid operation regarding PV power fluctuation are performed. Those are the scenarios when the PV generates the maximum power of $3325 \mathrm{~kW}$ and abruptly drops by $60 \%$ within a $1 \mathrm{~s}$ interval. The simulation is conducted for the minimum and maximum load conditions, as detailed in Scenarios 1 and 2 in Table 2. In these two scenarios, the ESS converter size is assumed to be sufficient to absorb all the surplus power produced by PVs. Online diesel generators operate at their minimum loading requirements, which is $25 \%$ of their rated power. Scenario 3 considers a smaller ESS converter to see the microgrid dynamic behavior when over-generation happens in the worst case. These three scenarios are simulated using the developed microgrid model in PowerFactory. The system frequency and voltage magnitudes at critical points are measured. The simulation results are shown in Figures 11-13.

Table 2. Description of dynamic simulation scenarios.

\begin{tabular}{|c|c|c|c|}
\hline Scenario & Simulation Conditions & Operating Units & Simulation Event \\
\hline 1 & $\begin{array}{l}\text { Minimum load }(700 \mathrm{~kW}) \\
\text { Maximum PV generation }(3325 \mathrm{~kW})\end{array}$ & $\begin{array}{l}2 \text { Diesel }(300 \mathrm{~kW} \times 2) \\
\text { ESS, PV, WT }\end{array}$ & PV output drops by $60 \%$ \\
\hline 2 & $\begin{array}{l}\text { Maximum load }(1900 \mathrm{~kW}) \\
\text { Maximum PV generation }(3325 \mathrm{~kW})\end{array}$ & $\begin{array}{c}4 \text { Diesel }(300 \mathrm{~kW} \times 2,500 \mathrm{~kW} \times 2) \\
\text { ESS, PV, WT }\end{array}$ & PV output drops by $60 \%$ \\
\hline 3 & $\begin{array}{l}\text { Minimum load }(700 \mathrm{~kW}) \\
\text { ESS converter is set to } 2500 \mathrm{~kW}\end{array}$ & $\begin{array}{l}2 \text { Diesel }(300 \mathrm{~kW} \times 2), \\
\text { ESS, PV, WT }\end{array}$ & PV output causes over-generation \\
\hline
\end{tabular}
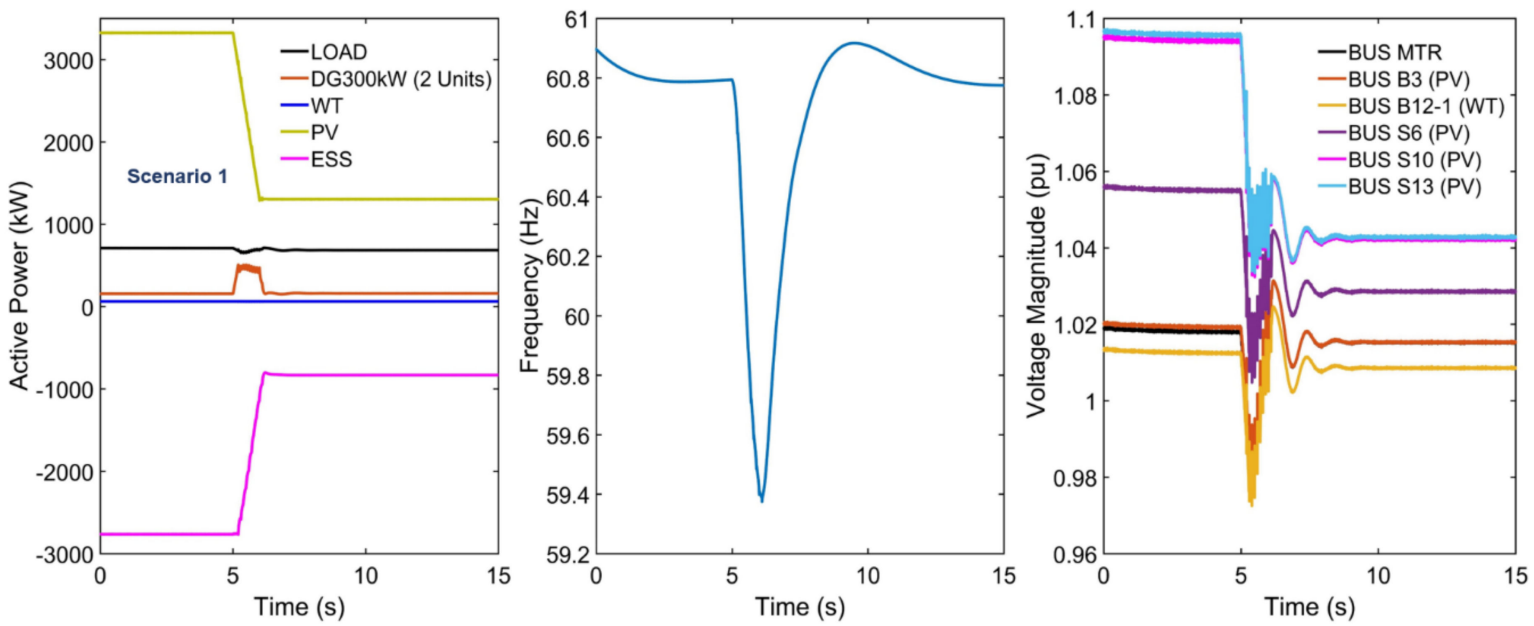

Figure 11. Active power, frequency, and voltage responses in Scenario 1. 

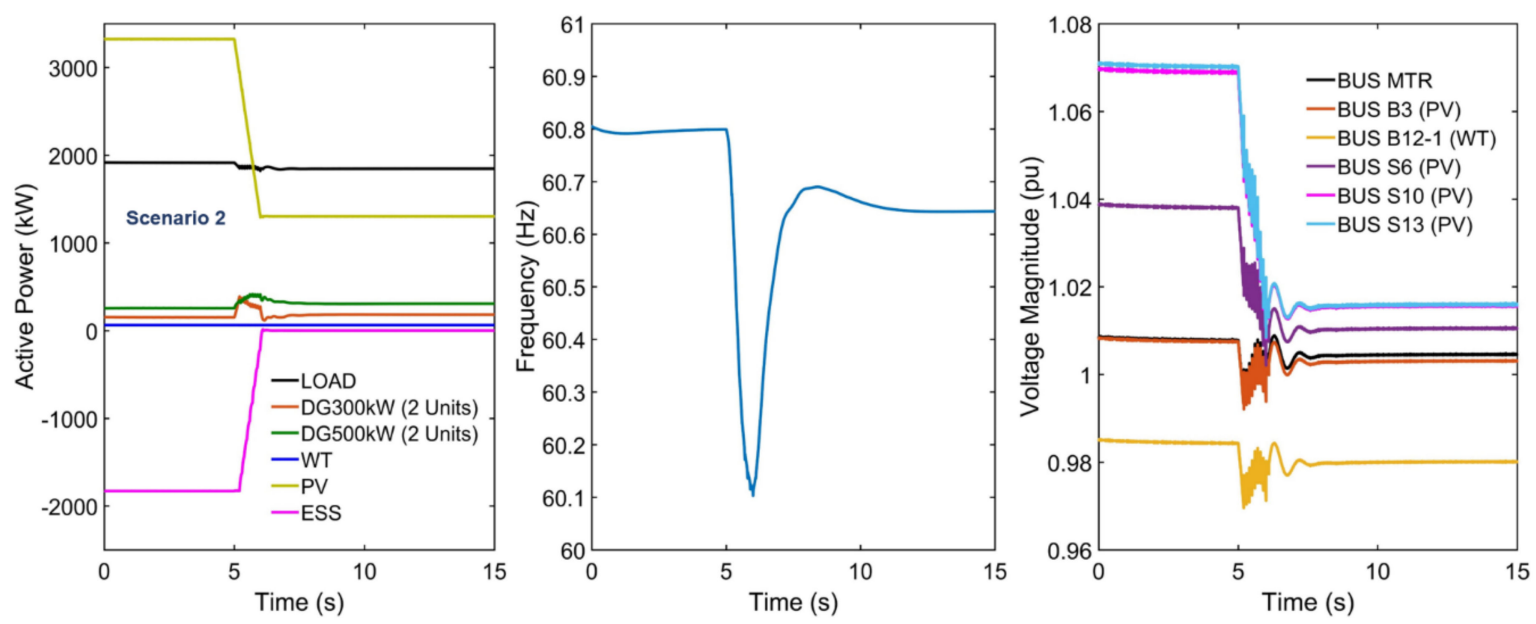

Figure 12. Active power, frequency, and voltage responses in Scenario 2.
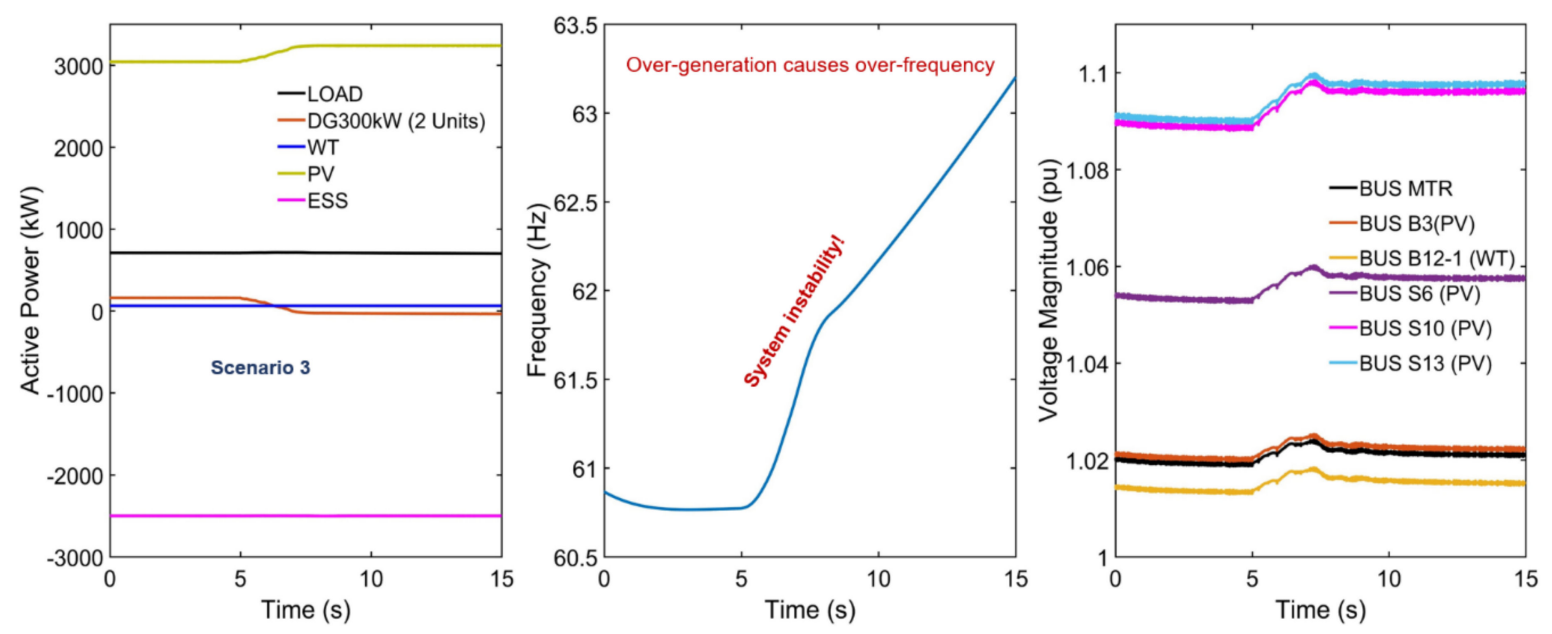

Figure 13. Active power, frequency, and voltage responses in Scenario 3.

The simulation results of Scenarios 1 and 2 justify the microgrid performance under sudden PV power fluctuations. The dynamic simulation results confirm no over-voltage problem if the total maximum PV power generation is limited to $3325 \mathrm{~kW}$. Under the worst PV output drop, variations occur in transient voltage and frequency responses, but these variations are within the voltage and frequency regulation ranges. These results verify the dynamic performance of Deokjeok Island microgrid.

In Scenario 3, the capacity of the ESS converter is confined to $2500 \mathrm{~kW}$. Under the minimum load of $700 \mathrm{~kW}$, diesel generators are operating at the minimum load and the surplus power from PVs is used to charge the ESS. When the output power of PVs increases more, the over-generation problem occurs. Consequently, the online diesel generators accelerate, as shown in Figure 13, which leads the system frequency to increase and triggers over-frequency relays to trip the diesel generators. In the worst case, this will cause system collapse and blackouts. The simulation results of Scenario 3 indicate the significance of the ESS converter size depending on the microgrid control structure.

From the analysis results, a design constraint on the ESS converter capacity is formed for the control structure of Deokjeok Island microgrid. Considering the minimum load ratio of diesel generators, which is typically $25 \%$ of the generator rating, and the extreme 
case of surplus power from RESs, the required capacity of the ESS converter must satisfy the constraint in Equation (5).

$$
E S S_{\text {Converter }} \geq R E S_{\text {max }}+0.25 \text { Load }_{\text {min }}-\text { Load }_{\text {min }}
$$

where $E S S_{\text {Converter }}(\mathrm{kW})$ is the required capacity of the ESS converter, $R E S_{\max }(\mathrm{kW})$ is the admissible maximum output power of the RES, and Load $_{\min }(\mathrm{kW})$ is the minimum load of the microgrid.

In summary, the power system analysis was performed for Deokjeok Island microgrid based on critical problems of RES integration. The analysis results identified two design constraints to guarantee the power system performance. The first constraint is that the total maximum output power of PV plants must be limited to $3325 \mathrm{~kW}$ to eliminate the over-voltage issue. The second constraint is that the ESS converter capacity must be sufficient as determined by Equation (5) to address the over-generation problem. These two constraints are applied as hard constraints in the techno-economic analysis to find the optimal microgrid configuration.

\section{Techno-Economic Analysis for Microgrid Design}

In this study, the optimal design of Deokjeok Island microgrid aims to maximize the system economic efficiency with renewable energy integration, which can be evaluated by the total net present cost (NPC) and levelized cost of energy (LCOE). NPC addresses all the costs and revenues occurring within the project lifetime, with future cash flows discounted back to the present using the real discount rate [53]. For stand-alone systems, NPC includes the costs of initial installation, component replacement, maintenance, fuel consumption, and miscellaneous costs such as emission penalty if applicable, and the revenue of salvage value that occurs at the end of the project lifetime [53]. NPC is calculated using the following equations.

$$
\begin{gathered}
\operatorname{CRF}(i, N)=\frac{i(1+i)^{N}}{(1+i)^{N}-1} \\
N P C=\frac{C_{a n n, t o t}}{\operatorname{CRF}(i, N)}
\end{gathered}
$$

where $C R F$ is the capital recovery factor, $i(\%)$ is the annual real discount rate, $N(\mathrm{y})$ is the project lifetime, NPC (\$) is the total net present cost, and $C_{a n n, t o t}(\$)$ is the total annualized cost.

LCOE is the average cost for each kilowatt-hour of useful electrical energy generated by the designed power system [53]. HOMER determines the LCOE using Equation (8). The optimal design seeks for the microgrid configuration with the lowest LCOE and NPC.

$$
L C O E=\frac{C_{a n n, t o t}}{E_{\text {prim }, s}+E_{d e f, s}}
$$

where $\operatorname{LCOE}(\$ / \mathrm{kWh})$ is the levelized cost of energy, $E_{\text {prim }, s}(\mathrm{kWh})$ and $E_{\text {def,s }}(\mathrm{kWh})$ are the total amounts of primary energy demand and deferrable energy demand served by the system in one year, respectively.

\subsection{Input Data}

As indicated in the proposed microgrid design framework, in addition to the design constraints obtained from the power system analysis, the input data for techno-economic analysis include load demand and renewable energy resources data for a complete year with a typical time-step of $1 \mathrm{~h}$, the associated costs of DER technologies, and financial parameters for the calculation of economic metrics. It is apparent that the accuracy of input data predominantly decides the quality of analysis results. This section describes the preparation of input data in detail. 


\subsubsection{Load Demand}

There are several methods to construct an energy consumption profile for various types of customers. The widely applied approaches include survey, regression, and datadriven. The survey method uses question forms to collect the information of the electricity demand of each individual customer or representative customers $[54,55]$. The regression method is a statistical technique to model the load profile based on associated variables such as the numbers of industrial, commercial, and residential customers, education level, income and major economic activities, and population growth rates [56]. The data-driven approach estimates the load demand based on the measured data of existing loads [55]. Among the above-mentioned techniques, the data-driven approach is perhaps the most reliable and accurate for load estimation, which is adopted in this study. This method can be applicable in well-designed and developed systems with an energy management system (EMS), in which the electricity demand has been measured and recorded for certain periods.

Based on the available measured data of Deokjeok Island, the load profile of the whole island for a complete year was constructed. The island has maximum, average, and minimum loads of 1900,1190, and $700 \mathrm{~kW}$, respectively. The relatively high load factor of 0.63 partly shows the potential for renewable energy penetration. Figure 14 describes several representative features of the load profile for the Deokjeok Island microgrid design.
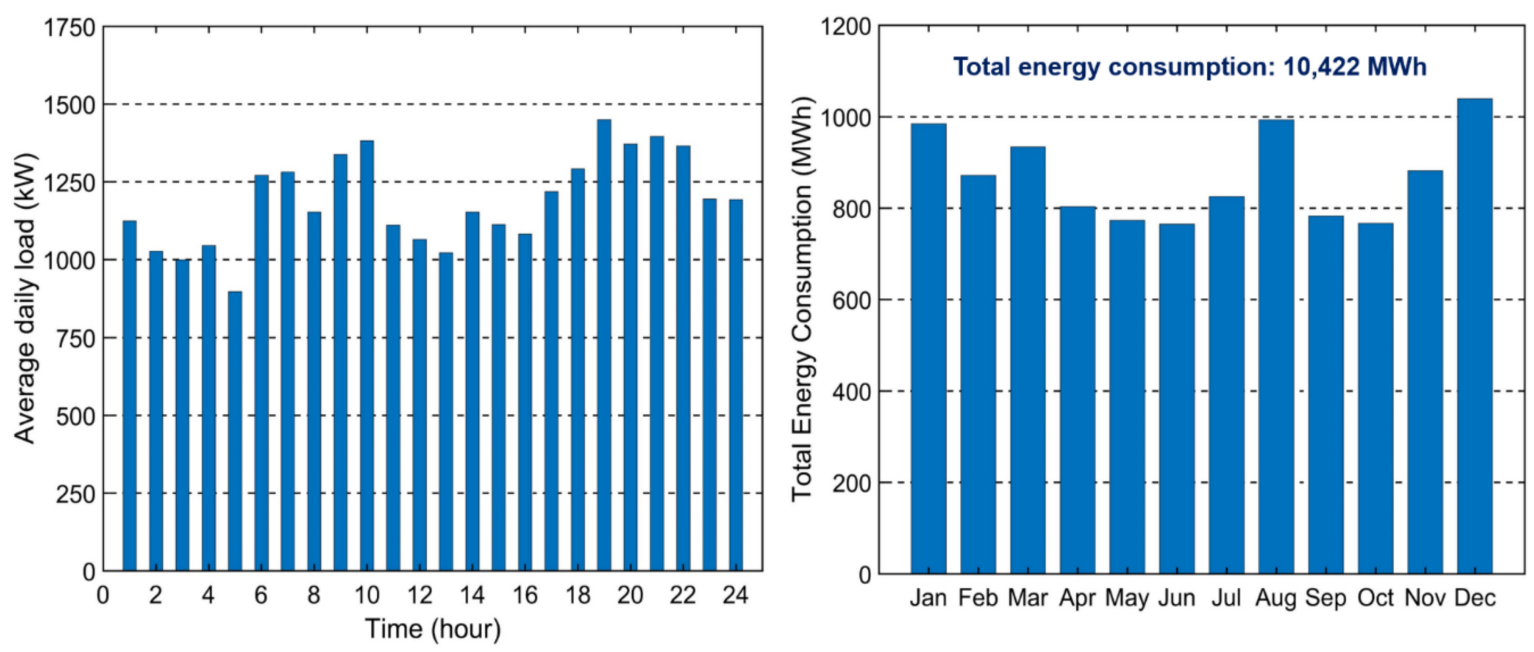

Figure 14. The average daily load profile and monthly energy consumption of Deokjeok Island.

\subsubsection{Renewable Energy Resources}

The time-series data of renewable energy resources, including solar irradiance, wind speed, and temperature for one year, are required to evaluate the energy production of WTs and PVs. However, the on-site measurement data of these weather resources are not available at Deokjeok Island. Instead, the data of global horizontal irradiance (GHI), wind speed, and temperature were downloaded from the NASA Surface Meteorology website for the coordinates of Deokjeok Island $\left(37^{\circ} 14.3^{\prime} \mathrm{N}, 126^{\circ} 7.7^{\prime} \mathrm{E}\right)$ [57]. This approach is commonly used for obtaining the renewable energy resources data used for the technoeconomic analysis, and this functionality is embedded in HOMER for the user convenience. Figure 15 shows the key statistics of the availability of solar irradiance and wind speed at the site. 

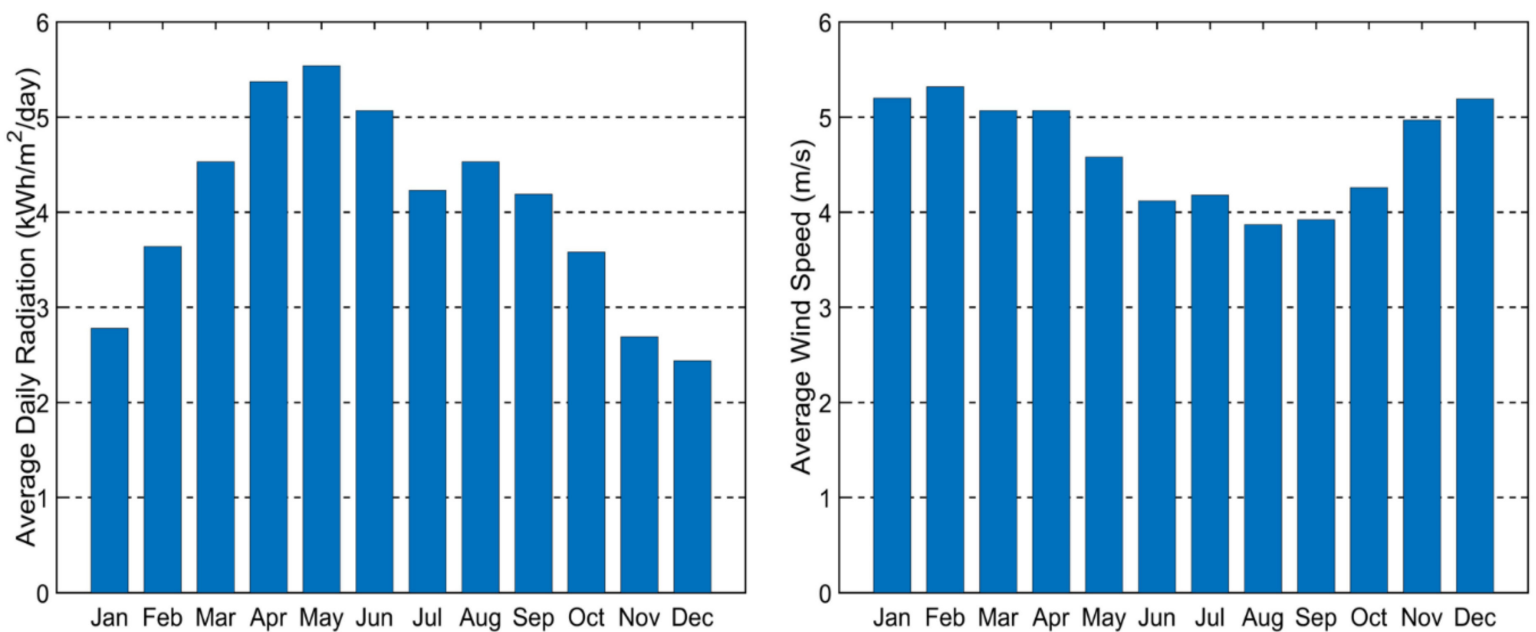

Figure 15. The average daily radiation and average wind speed at Deokjeok Island.

\subsubsection{DER Costs and Project Finance}

It is obvious that the costs of DER technologies directly affect their capacity in the optimal microgrid design. The costs of DERs vary significantly depending on many properties such as the manufacturing technology, rated capacity and installation scale, local market policies, and applicable technical features. Based on the surveyed data, the associated costs and parameters of DER technologies are listed in Table 3. Table 4 presents the financial parameters of the local market used for economic calculation. The project lifetime is considered to be 25 years.

Table 3. Associated costs and parameters of DER technologies.

\begin{tabular}{|c|c|c|c|}
\hline Technology & Costs and Parameters & Value & Unit \\
\hline \multirow{3}{*}{ PV [58] } & Capital cost & 1500 & $\$ / \mathrm{kW}$ \\
\hline & O\&M cost & 10 & $\$ / \mathrm{kW} / \mathrm{y}$ \\
\hline & Lifetime & 25 & $\mathrm{y}$ \\
\hline \multirow{3}{*}{ WT [58] } & Capital cost & 2500 & $\$ / \mathrm{kW}$ \\
\hline & O\&M cost & 30 & $\$ / \mathrm{kW} / \mathrm{y}$ \\
\hline & Lifetime & 25 & $\mathrm{y}$ \\
\hline \multirow{5}{*}{ ESS Battery Bank [59] } & Capital cost & 450 & $\$ / \mathrm{kWh}$ \\
\hline & O\&M cost & 10 & $\$ / \mathrm{kWh} / \mathrm{y}$ \\
\hline & Replacement cost & 225 & $\$ / \mathrm{kWh}$ \\
\hline & Throughput & 3000 & $\mathrm{kWh} /$ unit \\
\hline & Round-trip efficiency & 90 & $\%$ \\
\hline \multirow{4}{*}{ ESS Converter [59] } & Capital cost & 200 & $\$ / \mathrm{kW}$ \\
\hline & Replacement cost & 200 & $\$ / \mathrm{kW}$ \\
\hline & Efficiency & 98 & $\%$ \\
\hline & Lifetime & 12.5 & $\mathrm{y}$ \\
\hline \multirow{6}{*}{ Diesel Generator [3] } & Capital cost & 500 & $\$ / \mathrm{kW}$ \\
\hline & $\mathrm{O} \& \mathrm{M}$ cost & 0.03 & $\$ / \mathrm{kW} / \mathrm{h}$ \\
\hline & Replacement cost & 500 & $\$ / \mathrm{kW}$ \\
\hline & Lifetime & 60,000 & $\mathrm{~h}$ \\
\hline & Minimum load ratio & 25 & $\%$ \\
\hline & Diesel fuel price & 1.1 & $\$ / L$ \\
\hline
\end{tabular}


Table 4. Financial parameters.

\begin{tabular}{ccc}
\hline Parameter & Value & Unit \\
\hline Nominal discount rate & 8 & $\%$ \\
Inflation rate & 2.38 & $\%$ \\
Real discount rate & 5.49 & $\%$ \\
Project lifetime & 25 & $\mathrm{y}$ \\
\hline
\end{tabular}

\subsection{Techno-Economic Results and Optimal Design}

The techno-economic analysis is performed for Deokjeok Island microgrid using the above-presented input data and the design constraints obtained from the power system analysis. The decision metrics on the system economic efficiency include LCOE and NPC. An extensive set of various microgrid configurations considering different PV rated capacities was simulated in HOMER. According to the constraints identified from the power system analysis, for the microgrid configurations with a PV rated capacity greater than $3325 \mathrm{~kW}$, the output power of the PV is limited by $3325 \mathrm{~kW}$, and the ESS converter must be greater than or equal to $2900 \mathrm{~kW}$. The results of the LCOE and NPC are summarized in Figure 16.

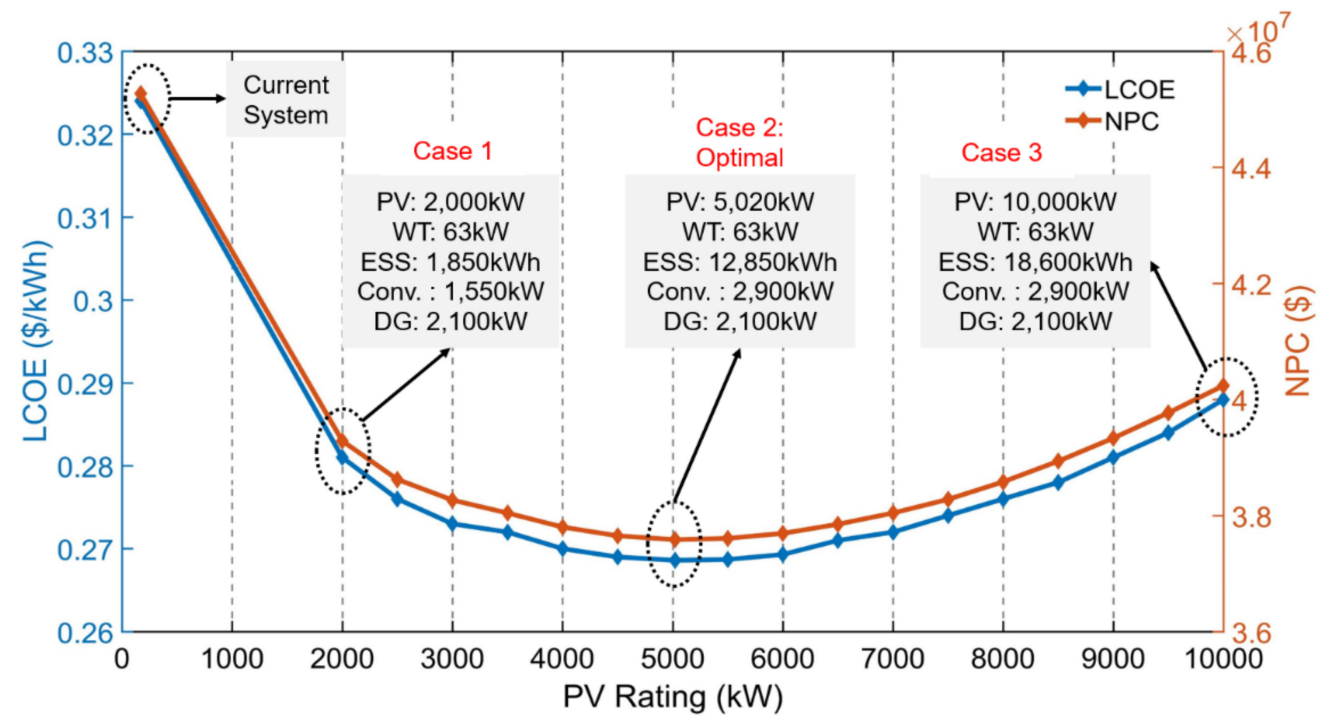

Figure 16. Levelized cost of energy (LCOE) and net present cost (NPC) for various PV capacities for Deokjeok Island microgrid.

The economic results reveal that the microgrid LCOE and NPC decrease significantly with PV and ESS integration compared to those of the current system. Under the design constraints, the system LCOE reaches a minimum at $0.269 \$ / \mathrm{kWh}$ in the configuration with the PV of $5020 \mathrm{~kW}$ and the ESS with a battery bank of 12,850 kWh and a converter of $2900 \mathrm{~kW}$. For more accurate comparisons, Table 5 presents detailed results of the selected configurations, and Figure 17 gives a graphical comparison of their key economic measures.

In the current power system of Deokjeok Island, the annual renewable energy penetration is only $3.0 \%$, and the system consumes approximately 2,556,508 L/y of diesel fuel, which contributes significantly to the annual operating cost of 3,232,571 $\$ / y$. In the optimal microgrid configuration, the penetration level of energy production from PVs and WTs reaches $59.3 \%$. As a result, a significant amount of fuel consumed by diesel generators is saved. The annual fuel consumption is $1,087,777 \mathrm{~L} / \mathrm{y}$, which decreases by more than a half compared to that of the current system, leading to a considerable reduction in the system operating cost to $1,674,429 \$ / y$. Compared to the current system, the NPC of the optimal configuration declines by $\$ 7,683,550$. 
Table 5. Results of selected cases for Deokjeok Island microgrid.

\begin{tabular}{|c|c|c|c|c|c|}
\hline Parameter & Unit & $\begin{array}{l}\text { Current } \\
\text { System }\end{array}$ & Case 1 & $\begin{array}{c}\text { Case } 2 \\
\text { (Optimal) }\end{array}$ & Case 3 \\
\hline \multicolumn{6}{|l|}{ DERs Sizing } \\
\hline PV & $\mathrm{kW}$ & 169 & 2000 & 5020 & 10,000 \\
\hline WT & $\mathrm{kW}$ & 63 & 63 & 63 & 63 \\
\hline ESS & $\mathrm{kWh}$ & - & 1850 & 12,850 & 18,600 \\
\hline ESS converter & $\mathrm{kW}$ & - & 1550 & 2900 & 2900 \\
\hline Diesel generator & $\mathrm{kW}$ & 2900 & 2100 & 2100 & 2100 \\
\hline \multicolumn{6}{|l|}{ Energy Production } \\
\hline PV & $\mathrm{kWh} / \mathrm{y}$ & 264,949 & $2,888,518$ & $6,473,993$ & $8,917,634$ \\
\hline $\mathrm{WT}$ & $\mathrm{kWh} / \mathrm{y}$ & 49,448 & 49,448 & 49,448 & 49,448 \\
\hline Diesel generator & $\mathrm{kWh} / \mathrm{y}$ & $10,107,980$ & $7,529,622$ & $4,246,593$ & $2,032,597$ \\
\hline Fuel consumption & $\mathrm{L} / \mathrm{y}$ & $2,556,508$ & $1,922,135$ & $1,087,777$ & 522,868 \\
\hline RES penetration & $\%$ & 3.0 & 27.8 & 59.3 & 80.5 \\
\hline \multicolumn{6}{|l|}{ Economic Metrics } \\
\hline LCOE & $\$ / \mathrm{kWh}$ & 0.324 & 0.281 & 0.269 & 0.288 \\
\hline NPC & $\$$ & $45,267,580$ & $39,284,640$ & $37,584,030$ & $40,238,770$ \\
\hline Capital cost & $\$$ & $1,861,000$ & $5,350,000$ & $15,100,000$ & $25,157,500$ \\
\hline Operating cost & $\$ / y$ & $3,232,571$ & $2,527,178$ & $1,674,429$ & $1,123,131$ \\
\hline
\end{tabular}

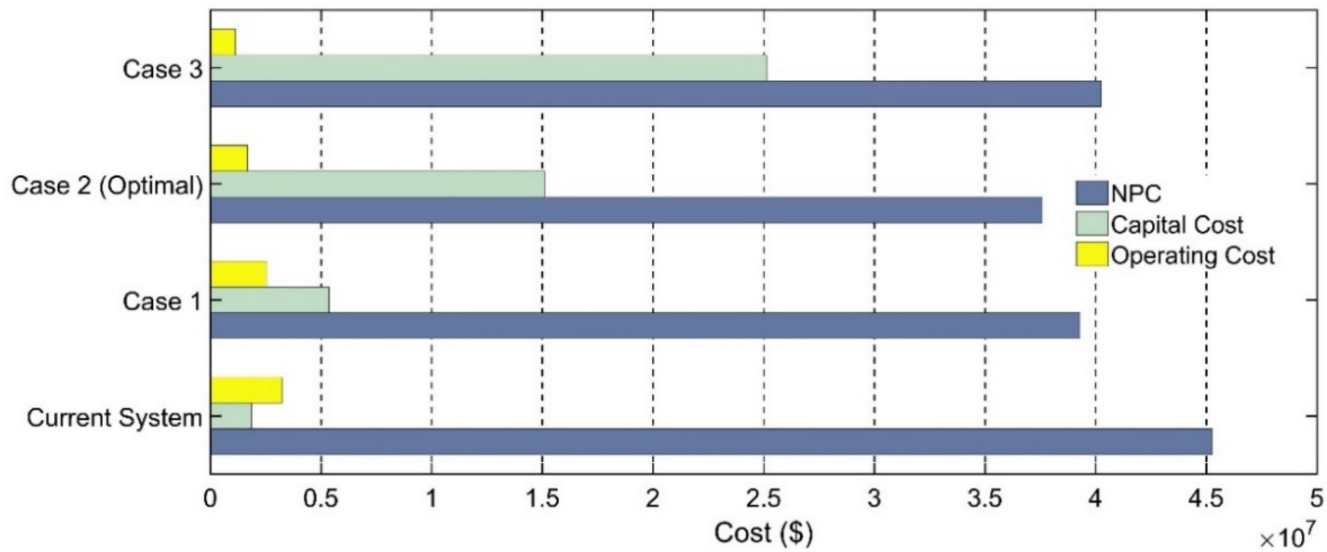

Figure 17. Cost comparison of selected cases for Deokjeok Island microgrid.

It is clear that higher PV capacity results in more fuel saving, producing lower system operating costs and higher renewable energy penetration. When the rated PV capacity increases from 2000 to $10,000 \mathrm{~kW}$, the annual energy penetration ratio of RESs increases from $27.8 \%$ to $80.5 \%$. In the microgrid configuration with a PV of $10,000 \mathrm{~kW}$, the annual fuel consumption is only $522,868 \mathrm{~L} / \mathrm{y}$, which is approximately one-fifth of that in the current system. However, in the case integrating $10,000 \mathrm{~kW} \mathrm{PV}$, it must be noticed that the system LCOE and NPC are $0.288 \$ / \mathrm{kWh}$ and $\$ 40,238,770$, respectively, which are higher than those of the optimal case. This is because of the significantly higher capital cost of $\$ 25,157,500$ for larger PV and ESS plants. Subsequently, the savings in system operating costs are insufficient to reduce the LCOE and NPC compared to the optimal configuration.

The techno-economic analysis for the Deokjeok Island microgrid design verifies the system economic efficiency for higher PV and ESS integration. The results indicate that the microgrid configurations with higher PV and ESS result in higher renewable energy penetration levels and lower system operating costs, primarily due to the considerable fuel savings. However, excessive PV and ESS capacity can increase the system LCOE and NPC due to high capital costs.

From the analysis results, there is an optimal microgrid configuration, as highlighted in Figure 16 and Table 5, in which the system LCOE and NPC reach the minimum values. 
As the design objective of Deokjeok Island microgrid is to maximize the system economic efficiency, which means the lowest LCOE and NPC for stand-alone microgrids, the microgrid configuration with $5020 \mathrm{~kW}$ PV, $63 \mathrm{~kW}$ WT, the ESS with a 12,850 kWh battery bank and $2900 \mathrm{~kW}$ converter, and $2100 \mathrm{~kW}$ diesel generators is selected for the optimal design considering the current power system conditions of the island and the microgrid control structure presented in Figure 3.

\section{Impacts of Technical Improvements on Optimal Design}

This section aims to evaluate whether some technical improvements in the power system structure can increase the microgrid economic efficiency, hence resulting in a better optimal design. As presented, the two design constraints identified from the power system analysis for Deokjeok Island microgrid are the maximum output power of PVs due to the over-voltage problem, and the required ESS converter capacity due to the over-generation problem. The solutions to improve the power system performance regarding these two problems are considered. The solutions include power system reconfiguration to improve the system voltage profile under high renewable energy generation, and real-time control of PV output power to address the over-generation issue.

\subsection{Power System Reconfiguration}

With the existing feeder configuration shown in Figure 2, it was found that the total output power of PV systems must be limited to $3325 \mathrm{~kW}$ to prevent the over-voltage problem, which will trigger over-voltage relays and may lead to RES disconnections or even cascading outages. The most technically efficient and complete countermeasure for the over-voltage issue due to RES integration is to upgrade the distribution voltage to a higher voltage level. Specifically, for Deokjeok Island, the distribution voltage level can be upgraded to 22,900 V according to the voltage regulation in South Korea. However, upgrading the distribution voltage leads to the replacement of all transformers and possibly the type of conductor. Consequently, this solution is costly, requiring significant time and workforce for implementation.

Regarding these issues, there is a much simpler and less costly solution, which is to reconfigure the feeder configuration to enhance the system voltage profile. This solution can partially address the over-voltage issue. As presented, the existing power system of Deokjeok Island has two main feeders, two normally open tie lines, and sectionalizing switches installed along the feeders. These facilities sufficiently support power system reconfiguration without requiring additional equipment installation. Various system reconfigurations were examined. The option with the best voltage profile under high RES generation is presented in Figure 18.

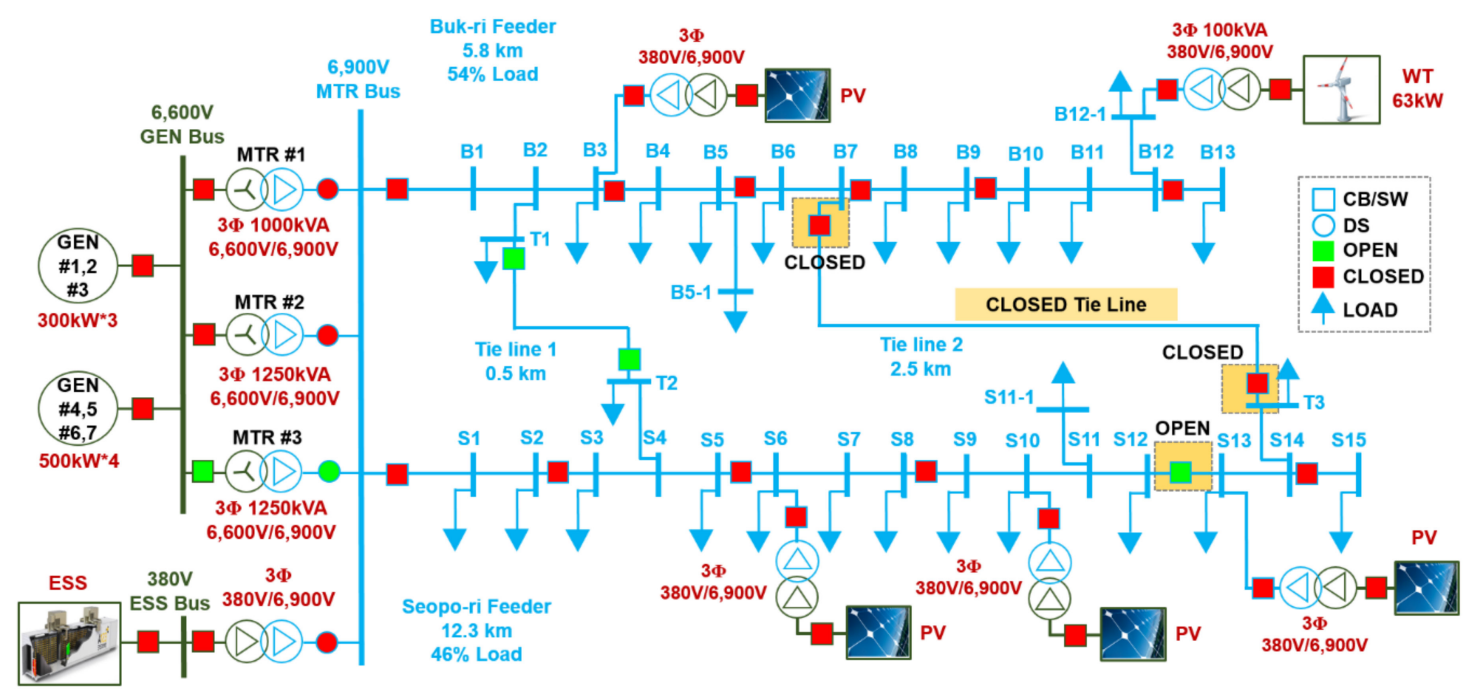

Figure 18. Power system reconfiguration for Deokjeok Island microgrid. 
The voltage profiles of this reconfigured system under different PV generation levels are shown in Figure 19. The results clearly justify the efficiency of power system reconfiguration in this case study. The total maximum output of PV plants can be extended to $5700 \mathrm{~kW}$, which is three times the peak demand. Due to the higher PV output power, the required capacity of the ESS converter must be upgraded accordingly. The techno-economic analysis for Deokjeok Island microgrid is performed again considering these updated design constraints due to the power system reconfiguration. The results are presented in Figure 20 and Table 6.
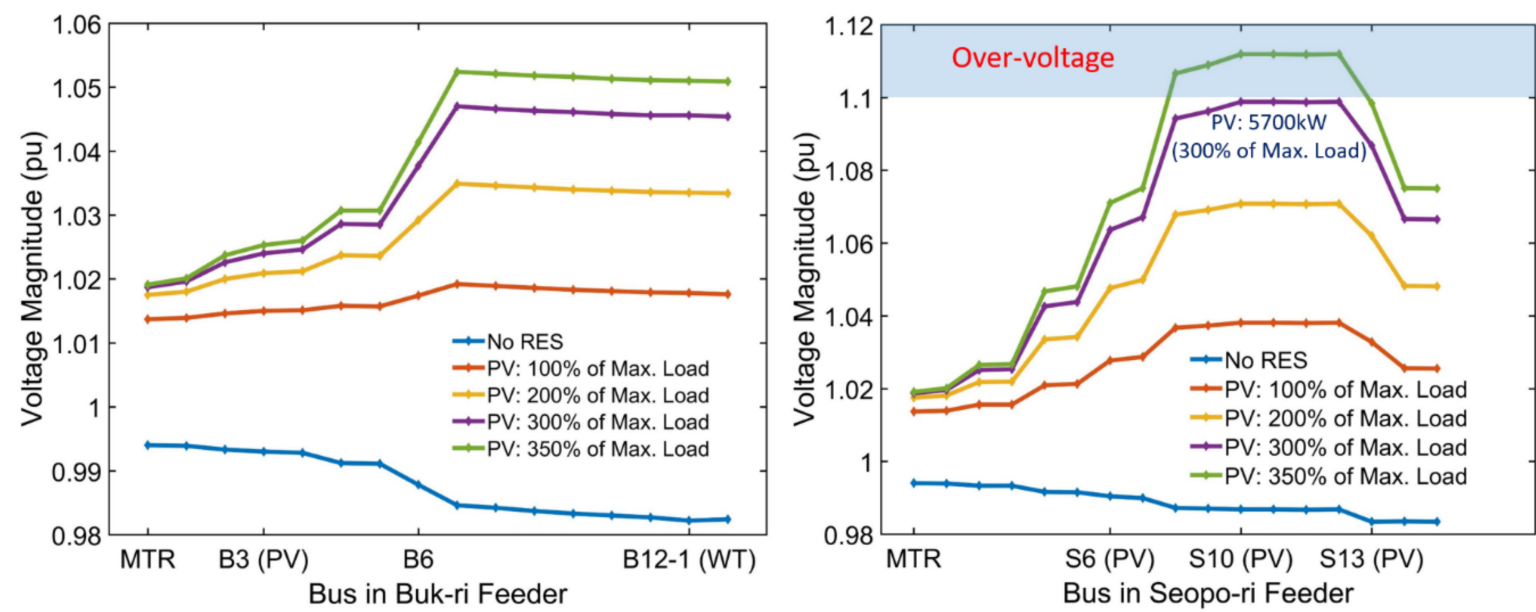

Figure 19. System voltage profile under minimum load and different PV generation levels considering power system reconfiguration.

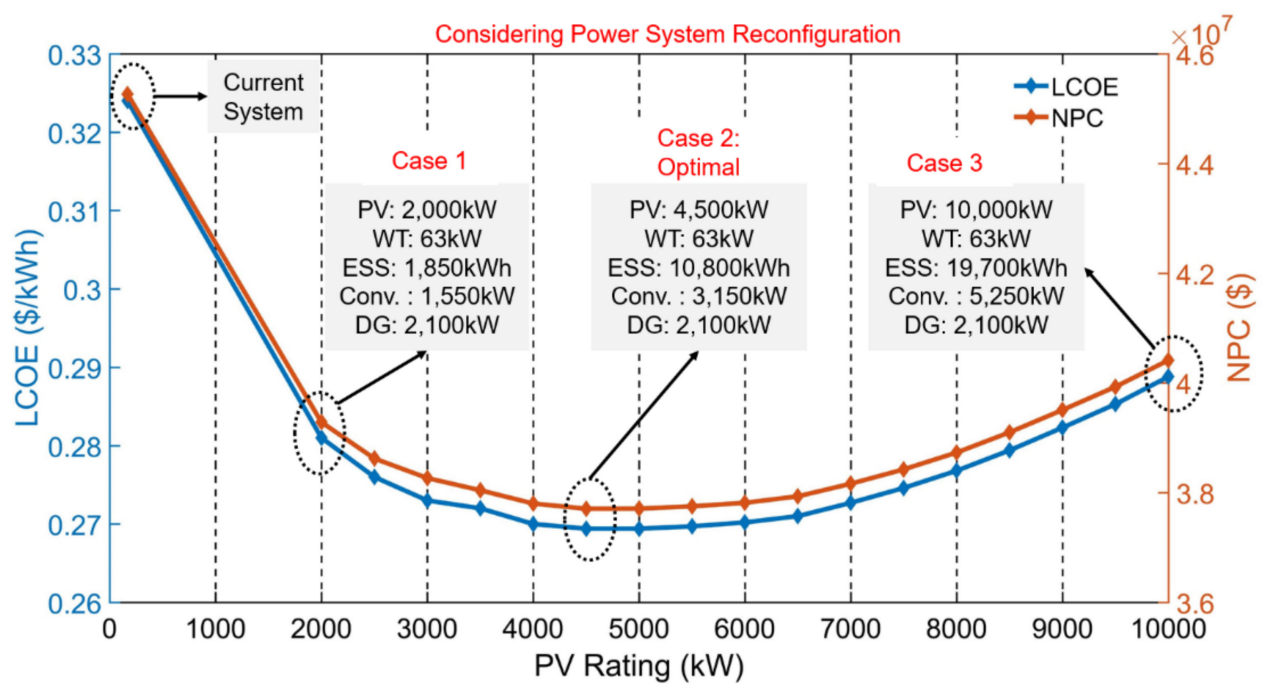

Figure 20. LCOE and NPC for various PV capacities considering power system reconfiguration. 
Table 6. Results of selected cases for Deokjeok Island microgrid considering power system reconfiguration.

\begin{tabular}{ccccc}
\hline Parameter & Unit & Case 1 & $\begin{array}{c}\text { Case 2 } \\
\text { (Optimal) }\end{array}$ & Case 3 \\
\hline DERs Sizing & $\mathrm{kW}$ & 2000 & 4500 & 10,000 \\
PV & $\mathrm{kW}$ & 63 & 63 & 63 \\
WT & $\mathrm{kWh}$ & 1850 & 10,800 & 19,700 \\
ESS & $\mathrm{kW}$ & 1550 & 3150 & 5250 \\
ESS converter & $\mathrm{kW}$ & 2100 & 2100 & 2100 \\
Diesel generator & & & & \\
Energy Production & $\mathrm{kWh} / \mathrm{y}$ & $2,888,518$ & $5,895,037$ & $9,256,350$ \\
PV & $\mathrm{kWh} / \mathrm{y}$ & 49,448 & 49,448 & 49,448 \\
WT & $\mathrm{kWh} / \mathrm{y}$ & $7,529,622$ & $4,768,654$ & $1,733,127$ \\
Diesel generator & $\mathrm{L} / \mathrm{y}$ & $1,922,135$ & $1,220,112$ & 445,629 \\
Fuel consumption & $\%$ & 27.8 & 54.2 & 83.4 \\
RES penetration & & & & \\
\hline Economic Metrics & $\$ / \mathrm{kWh}$ & 0.281 & 0.269 & 0.289 \\
LCOE & $\$$ & $39,284,640$ & $37,706,790$ & $40,414,200$ \\
NPC & $\$$ & $5,350,000$ & $13,447,500$ & $26,122,500$ \\
Capital cost & $\$ / y$ & $2,527,178$ & $1,806,636$ & $1,064,330$ \\
\hline Operating cost & & &
\end{tabular}

The optimal configuration under the updated design constraints also produces the LCOE of $0.269 \$ / \mathrm{kWh}$. However, the system NPC is higher than that of the previously determined optimal configuration. The results indicate that the power system reconfiguration is efficient in improving the microgrid voltage profile but not in enhancing the microgrid economic efficiency. It should be noted that the reconfigured system considers the current system facilities and does not require additional costs. Furthermore, the original optimal configuration, which has $5020 \mathrm{~kW}$ PV with its output power limited to $3325 \mathrm{~kW}$, has a maximum voltage of nearly $1.1 \mathrm{pu}$. For these reasons, the combination of the original optimal configuration and the power system reconfiguration results in a better design for Deokjeok Island microgrid considering power system performance and economic efficiency.

\subsection{Real-Time PV Output Control}

In the control structure considered for Deokjeok Island microgrid, there is a requirement for the minimum capacity of the ESS converter to prevent the over-generation issue. An enhanced control feature of PV systems is considered based on the real-time control of PV output power to address this technical disadvantage. This technological feature requires additional communication links between the EMS and PV inverters. The PV inverters must be able to receive external power setpoints from the central controller, and generate the desired outputs accordingly by adjusting the PWM signals in their MPPT algorithm. It is obvious that the maximum power produced by PV systems depends on the available solar irradiation at a particular time. Therefore, this feature of PV output control curtails the PV power during real-time operation when needed to ensure other operating constraints of the microgrid. Implementing this feature of PV systems requires a fast and reliable communication technology at the site, and accurate measurements of system demand and generation status with very high measurement resolution. Based on the system loading conditions, the central controller calculates and sends control signals of power setpoints to PV and ESS systems. Consequently, there is no concern about the over-generation problem, and the microgrid can use a smaller ESS converter if it improves the system economic efficiency.

Considering the advantage of the real-time PV output control scheme, the technoeconomic analysis is performed again for Deokjeok Island microgrid. In addition, the extended maximum limit of PV generation, which is $5700 \mathrm{~kW}$ due to the power system 
reconfiguration, is considered in the simulation to minimize the PV power curtailment. The updated techno-economic results are presented in Figure 21 and Table 7.

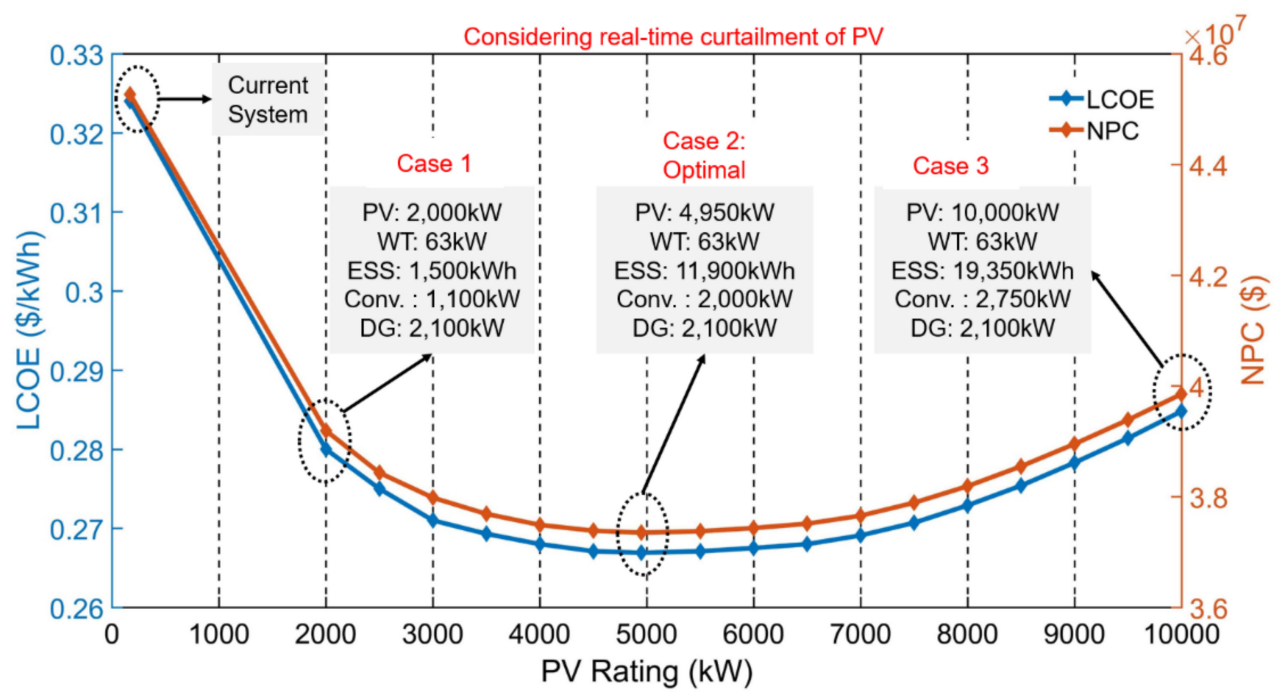

Figure 21. LCOE and NPC for various PV capacities considering real-time PV output curtailment.

Table 7. Results of selected cases for Deokjeok Island microgrid considering real-time PV output curtailment.

\begin{tabular}{ccccc}
\hline Parameter & Unit & Case 1 & $\begin{array}{c}\text { Case 2 } \\
\text { (Optimal) }\end{array}$ & Case 3 \\
\hline DERs Sizing & $\mathrm{kW}$ & 2000 & 4950 & 10,000 \\
PV & $\mathrm{kW}$ & 63 & 63 & 63 \\
WT & $\mathrm{kWh}$ & 1500 & 11,900 & 19,350 \\
ESS & $\mathrm{kW}$ & 1100 & 2000 & 2750 \\
ESS converter & $\mathrm{kW}$ & 2100 & 2100 & 2100 \\
Diesel generator & & & & \\
\hline Energy Production & $\mathrm{kWh} / \mathrm{y}$ & $2,828,871$ & $6,273,571$ & $9,135,683$ \\
PV & $\mathrm{kWh} / \mathrm{y}$ & 49,448 & 49,448 & 49,448 \\
WT & $\mathrm{kWh} / \mathrm{y}$ & $7,582,607$ & $4,424,375$ & $1,839,507$ \\
Diesel generator & $\mathrm{L} / \mathrm{y}$ & $1,937,123$ & $1,132,644$ & 472,696 \\
Fuel consumption & $\%$ & 27.2 & 57.5 & 82.4 \\
RES penetration & & & & \\
\hline Economic Metrics & $\$ / \mathrm{kWh}$ & 0.280 & 0.267 & 0.285 \\
LCOE & $\$$ & $39,192,520$ & $37,349,410$ & $39,853,060$ \\
NPC & $\$$ & $5,102,500$ & $14,387,500$ & $25,465,000$ \\
Capital cost & $\$ / y$ & $2,538,749$ & $1,710,018$ & $1,071,506$ \\
\hline Operating cost & & &
\end{tabular}

The results show that the microgrid control structure with the real-time PV output management effectively enhances the system economic efficiency. Overall, microgrid configurations under various PV ratings tend to select smaller ESS converters compared to the previously determined configurations in Table 5, which constrains the ESS converter size due to the over-generation problem. The optimal configuration integrates $4950 \mathrm{~kW} \mathrm{PV}$ and requires an ESS converter of only $2000 \mathrm{~kW}$, resulting in a system LCOE of $0.267 \$ / \mathrm{kWh}$ and NPC of $\$ 37,349,410$, which are lower than those of the original optimal case. It must be noted that this updated optimal case has both a capital cost and NPC lower than those of the original optimal case. Regarding the overall economic efficiency, the option requiring lower capital cost and NPC presents an economically attractive selection for investment. 


\subsection{Selection of Optimal Microgrid Design}

In summary, the design of Deokjeok Island microgrid was performed for three scenarios considering different power system conditions. The first scenario considered the existing power system configuration of the island and a simple and reliable microgrid control structure, which subsequently result in the constraints on the maximum PV output power and the required ESS converter capacity. The second scenario evaluated the system economic efficiency considering the power system reconfiguration to enhance the system voltage profile under high renewable energy penetration, hence extending the constraint of maximum PV generation. Finally, the third scenario considered an advanced microgrid control structure, which integrates the real-time PV output control so that the over-generation issue is figured out, and the extended PV output limit to minimize the power curtailment. The optimal microgrid configuration with the lowest LCOE and NPC was obtained for each scenario. Table 8 summarizes and compares the economic metrics of the three optimal configurations corresponding to the three scenarios.

Table 8. Summary of economic metrics of the optimal configurations for three scenarios.

\begin{tabular}{ccccc}
\hline Parameter & Unit & Scenario 1 & Scenario 2 & Scenario 3 \\
\hline DERs Sizing & & & & \\
PV & $\mathrm{kW}$ & 5020 & 4500 & 4950 \\
WT & $\mathrm{kW}$ & 63 & 63 & 63 \\
ESS & $\mathrm{kWh}$ & 12,850 & 10,800 & 11,900 \\
ESS converter & $\mathrm{kW}$ & 2900 & 3150 & 2000 \\
Diesel generator & $\mathrm{kW}$ & 2100 & 2100 & 2100 \\
\hline Economic Metrics & & & & \\
LCOE & $\$ / \mathrm{kWh}$ & 0.269 & 0.269 & 0.267 \\
NPC & $\$$ & $37,584,030$ & $37,706,790$ & $37,349,410$ \\
Capital cost & $\$$ & $15,100,000$ & $13,447,500$ & $14,387,500$ \\
Operating cost & $\$ / \mathrm{y}$ & $1,674,429$ & $1,806,636$ & $1,710,018$ \\
\hline
\end{tabular}

As analyzed, the optimal configuration of Scenario 3 has the highest economic efficiency with the lowest LCOE and NPC. The coordinated control scheme considered in Scenario 3 requires up-to-date technical features in the communication system and operation of DER units. With the technological development status of South Korea, it is guaranteed that all of these operation and control requirements are fulfilled. Recently, this country has been developing stand-alone and grid-connected microgrid models using stateof-the-art technologies to enhance the integration of RESs technically and economically. For these reasons, the microgrid configuration of Scenario 3 is selected for the final design.

In conclusion, based on the power system performance and economic efficiency, the optimal design of Deokjeok Island microgrid consists of $4950 \mathrm{~kW} \mathrm{PV}, 63 \mathrm{~kW} \mathrm{WT}$, the ESS with a battery bank of 11,900 kWh and a converter of $2000 \mathrm{~kW}$, and $2100 \mathrm{~kW}$ diesel generators. The microgrid control structure integrates the real-time PV output control, and the power system reconfiguration is selected to enhance the system's technical performance.

As presented, the proposed microgrid design framework was applied to the design of a stand-alone microgrid in Deokjeok Island for the design objective of minimizing the total system operating cost. The design framework can adapt to various microgrid planning and design problems under different objectives. For example, if a microgrid design aims to minimize the system carbon emission, the amount of emission in each feasible configuration must be calculated based on the system generation profile obtained from the performance model. When government or state incentives granted for renewable energy technology should be considered, annual cash flow calculation considering tax credits must be applied in the techno-economic analysis to capture all the benefits from available financial incentives for a microgrid project. Depending on particular design objectives, necessary modifications can be made in the techno-economic analysis to consider additional parameters. 


\section{Conclusions}

This paper proposed a microgrid design framework based on power system analysis and techno-economic analysis, which targets practical microgrid designs. Techno-economic analysis simulates the power balance of a microgrid considering economic prices and operating constraints of DER units, and the simulation is typically performed with annual operation data on a $1 \mathrm{~h}$ time-step resolution. Techno-economic analysis cannot evaluate the power system performance criteria, such as voltage and frequency regulations, which are essential for system operation when the microgrid design is implemented in practice. Accordingly, power system analysis is vital for a complete microgrid design. The optimal microgrid configuration obtained by the proposed method satisfies the design objective in terms of economic efficiency and the power system performance regulations, thereby enhancing the realistic feasibility of the microgrid design solution. The effectiveness of this approach was validated by applying it to a real stand-alone microgrid design for Deokjeok Island in South Korea.

The case study results justify the importance of considering power system specifications in the microgrid design process. The power system conditions affect not only the technical performance but also the optimal microgrid design. Considering the power system improvements, the selected optimal design for Deokjeok Island microgrid maximizes the system economic efficiency and provides high power system performance. This result indicates an advantageous application of the proposed microgrid design framework that is to evaluate the impacts of different power system design options on the optimal microgrid configuration. In practice, the planning and design of microgrids must consider local conditions of the site to obtain the most technically and economically feasible solution. This study can be a reference for microgrid designers seeking a complete microgrid design process that can be adopted in practical design problems and provides a means to evaluate technical and economic variants in the design solution.

The presented work in this paper has some limitations. The techno-economic analysis considered in the proposed microgrid design framework is based on deterministic calculation methods. We did not consider uncertainty in the required time-series data such as power demand and weather resources data. This is currently the most common approach in the microgrid planning and design process. However, this method cannot capture the intermittency in RES generation, which is a technical challenge in real-time microgrid operation for high renewable energy penetration. By incorporating power balance uncertainty in the performance model of the techno-economic analysis, the simulated operation of a microgrid can be more accurate for actual systems.

Author Contributions: Conceptualization, H.-J.L., B.H.V., R.Z., S.-W.H., and I.-Y.C.; investigation, H.-J.L.; methodology, H.-J.L., B.H.V. and R.Z.; formal analysis, I.-Y.C.; resources, H.-J.L. and S.-W.H.; writing—original draft preparation, B.H.V.; writing—review and editing, I.-Y.C.; supervision, I.-Y.C.; project administration, H.-J.L.; funding acquisition, H.-J.L. All authors have read and agreed to the published version of the manuscript.

Funding: This research was supported by the National Research Foundation of Korea (NRF) grant funded by the Korea government (MSIT) (No. 2019R1A2C1003880) and Korea Institute of Energy Technology Evaluation and Planning (KETEP) grant funded by the Korea government (MOTIE) (No. 2019371010006B).

Institutional Review Board Statement: Not applicable.

Informed Consent Statement: Not applicable.

Data Availability Statement: Not applicable.

Conflicts of Interest: The authors declare no conflict of interest. 


\section{References}

1. Ton, D.T.; Smith, M.A. The U.S. Department of Energy's Microgrid Initiative. Electr. J. 2012, 25, 84-94. [CrossRef]

2. Neves, D.; Silva, C.A.; Connors, S. Design and implementation of hybrid renewable energy systems on micro-communities: A review on case studies. Renew. Sustain. Energy Rev. 2014, 31, 935-946. [CrossRef]

3. Husein, M.; Hau, V.B.; Chung, I.Y.; Chae, W.K.; Lee, H.J. Design and Dynamic Performance Analysis of a Stand-alone MicrogridA Case Study of Gasa Island, South Korea. J. Electr. Eng. Technol. 2017, 12, 1777-1788.

4. Renteria, M.C.; Martin, D.S.; Guerrero, J.M. Microgrids Literature Review through Layers Structure. Energies $2019,12,4381$. [CrossRef]

5. Hirsch, A.; Parag, Y.; Guerrero, J. Microgrids: A review of technologies, key drivers, and outstanding issues. Renew. Sustain. Energy Rev. 2018, 90, 402-411. [CrossRef]

6. Pullins, S. Why microgrids are becoming an important part of the energy infrastructure. Electr. J. 2019, 32, 17-21. [CrossRef]

7. Parag, Y.; Ainspan, M. Sustainable microgrids: Economic, environmental and social costs and benefits of microgrid deployment. Energy Sustain. Dev. 2019, 52, 72-81. [CrossRef]

8. Adefarati, T.; Bansal, R.C. Reliability, economic and environmental analysis of a microgrid system in the presence of renewable energy resources. Appl. Energy 2019, 236, 1089-1114. [CrossRef]

9. Mohseni, S.; Brent, A.C.; Burmester, D. Community Resilience-Oriented Optimal Micro-Grid Capacity Expansion Planning: The Case of Totarabank Eco-Village, New Zeland. Energies 2020, 13, 3970. [CrossRef]

10. Elia, A.; Kamidelivand, M.; Rogan, F.; Gallachoir, B.O. Impacts of innovation on renewable energy technology cost reductions. Renew. Sustain. Energy Rev. 2020, in press. [CrossRef]

11. He, G.; Lin, J.; Sifuentes, F.; Liu, X.; Abhyankar, N.; Phadke, A. Rapid cost decrease of renewables and storage accelerates the decarbonization of China's power system. Nat. Commun. 2020, 11, 2486. [CrossRef] [PubMed]

12. Arani, A.A.K.; Gharehpetian, G.B.; Abedi, M. Review on Energy Storage Systems Control Methods in Microgrids. Inter. J. Electric. Power Energy Syst. 2019, 107, 745-757. [CrossRef]

13. Hajiaghasi, S.; Salemnia, A.; Hamzeh, M. Hybrid energy storage system for microgrids applications: A review. J. Energy Storage 2019, 21, 543-570. [CrossRef]

14. Jung, J.; Villaran, M. Optimal planning and design of hybrid renewable energy systems for microgrids. Renew. Sustain. Energy Rev. 2017, 75, 180-191. [CrossRef]

15. Sachs, J.; Sawodny, O. Multi-objective three stage design optimization for island microgrids. Appl. Energy 2016, 165, 789-800. [CrossRef]

16. Vu, B.H.; Husein, M.; Kang, H.K.; Chung, I.Y. Optimal Design for a Campus Microgrid Considering ESS Discharging Incentive and Financial Feasibility. J. Electr. Eng. Technol. 2019, 14, 1095-1107. [CrossRef]

17. Hau, V.B.; Husein, M.; Chung, I.Y.; Won, D.J.; Torre, W.; Nguyen, T. Analyzing the Impact of Renewable Energy Incentives and Parameter Uncertainties on Financial Feasibility of a Campus Microgrid. Energies 2018, 11, 2446. [CrossRef]

18. Husein, M.; Chung, I.Y. Optimal design and financial feasibility of a university campus microgrid considering renewable energy incentives. Appl. Energy 2018, 225, 273-289. [CrossRef]

19. Cao, T.; Hwang, Y.; Radermacher, R. Development of an optimization based design framework for microgrid energy systems. Energy 2017, 140, 340-351. [CrossRef]

20. Sallam, A.M.; Ahmed, H.M.A.; Salama, M.M.A. A planning framework for AC-DC bilayer microgrids. Electr. Power Syst. Res. 2020, 188, 106524. [CrossRef]

21. Santos, A.Q.; Ma, Z.; Olsen, C.G.; Jorgensen, B.N. Framework for Microgrid Design Using Social, Economic, and Technical Analysis. Energies 2018, 11, 2832. [CrossRef]

22. Kumar, A.; Singh, A.R.; Deng, Y.; He, X.; Kumar, P.; Bansal, R.C. A novel methodological framework for the design of sustainable rural microgrid for developing nations. IEEE Access 2018, 6, 24925-24951. [CrossRef]

23. Zhao, B.; Zhang, X.; Li, P.; Wang, K.; Xue, M.; Wang, C. Optimal sizing, operating strategy and operational experience of a stand-alone microgrid on Dongfushan Island. Appl. Energy 2014, 113, 1656-1666. [CrossRef]

24. Hafez, O.; Bhattacharya, K. Optimal planning and design of a renewable energy based supply system for microgrids. Renew. Energy 2012, 45, 7-15. [CrossRef]

25. Jamshidi, M.; Askarzadeh, A. Techno-economic analysis and size optimization of an off-grid hybrid photovoltaic, fuel cell and diesel generator system. Sustain. Cities Soc. 2019, 44, 310-320. [CrossRef]

26. Yoshida, Y.; Farzaneh, H. Optimal Design of a Stand-Alone Residential Hybrid Microgrid System for Enhancing Renewable Energy Deployment in Japan. Energies 2020, 13, 1737. [CrossRef]

27. Koutroulis, E.; Kolokotsa, D.; Potirakis, A.; Kalaitzakis, K. Methodology for optimal sizing of stand-alone photovoltatic/windgenerator systems using genetic algorithms. Sol. Energy 2006, 80, 1072-1088. [CrossRef]

28. Yang, H.; Zhou, W.; Lu, L.; Fang, Z. Optimal sizing method for stand-alone hybrid solar-wind system with LPSP technology by using genetic algorithm. Sol. Energy 2008, 82, 354-367. [CrossRef]

29. Senjyu, T.; Hayashi, D.; Yona, A.; Urasaki, N.; Funabashi, T. Optimal configuration of power generating systems in isolated island with renewable energy. Renew. Energy 2007, 32, 1917-1933. [CrossRef]

30. Bukar, A.L.; Tan, C.W.; Lau, K.Y. Optimal sizing of an autonomous photovoltaic/wind/battery/diesel generator microgrid using grasshopper optimization algorithm. Sol. Energy 2019, 188, 685-696. [CrossRef] 
31. Pecenak, Z.K.; Stadler, M.; Mathiesen, P.; Fahy, K.; Kleissl, J. Robust design of microgrids using a hybrid minimum investment optimization. Appl. Energy 2020, 276, 115400. [CrossRef]

32. Shi, K.; Ye, H.; Song, W.; Zhou, G. Virtual Inertia Control Strategy in Microgrid Based on Virtual Synchronous Generator Technology. IEEE Access 2018, 6, 27949-27957. [CrossRef]

33. Yoo, C.H.; Chung, I.Y.; Lee, H.J.; Hong, S.S. Intelligent Control of Battery Energy Storage for Multi-Agent Based Microgrid Energy Management. Energies 2013, 6, 4956-4979. [CrossRef]

34. Gonzalez-Longatt, F.M.; Rueda, J.L. PowerFactory Applications for Power System Analyis; Springer: Cham, Switzerland, 2014.

35. Bonfiglio, A.; Brignone, M.; Invernizzi, M.; Labella, A.; Mestriner, D.; Procopio, R. A Simplified Microgrid Model for the Validation of Islanded Control Logics. Energies 2017, 10, 1141. [CrossRef]

36. Ibrahim, L.O.; Sung, Y.M.; Hyun, D.; Yoon, M. A Feasibility Study of Frequency Regulation Energy Storage System Installation in a Power Plant. Energies 2020, 13, 5365. [CrossRef]

37. Ameur, A.; Loudiyi, K.; Aggour, M. Steady State and Dynamic Analysis of Renewable Energy Integration into the Grid using PSS/E Software. Energy Procedia 2017, 141, 119-125. [CrossRef]

38. Bahramara, S.; Moghaddam, M.P.; Haghifam, M.R. Optimal planning of hybrid renewable energy systems using HOMER: A review. Renew. Sustain. Energy Rev. 2016, 62, 609-620. [CrossRef]

39. Lopez, R.D.; Agustin, J.L.B. Design and control strategies of PV-Diesel systems using genetic algorithms. Sol. Energy 2005, 79, 33-46. [CrossRef]

40. Stadler, M.; Groissbock, M.; Cardoso, G.; Marnay, C. Optimizing Distributed Energy Resources and building retrofits with the strategic DER-CAModel. Appl. Energy 2014, 132, 557-567. [CrossRef]

41. Blair, N.; Dobos, A.P.; Freeman, J.; Neises, T.; Wagner, M.; Ferguson, T.; Gilman, P.; Janzou, S. System Advisor Model, SAM 2014.1.14: General Description; NREL: Golden, CO, USA, 2014.

42. Natural Resources Canada. Clean Energy Project Analysis: RETScreen Engineering E Cases Textbook, 3rd ed.; Natural Resources Canada: Hamilton, ON, Canada, 2005.

43. Rocabert, J.; Luna, A.; Blaabjerg, F.; Rodriguez, P. Control of Power Converters in AC Microgrids. IEEE Trans. Power Electron. 2012, 27, 4734-4749. [CrossRef]

44. Ropp, M.E.; Gonzalez, S. Development of a MATLAB/Simulink Model of a Single-Phase Grid-Connected Photovoltaic System. IEEE Trans. Energy Convers. 2009, 24, 195-202. [CrossRef]

45. Masters, G.M. Renewable and Efficient Electric Power Systems; John Wiley \& Sons: Hoboken, NJ, USA, 2004.

46. Bellia, H.; Youcef, R.; Fatima, M. A detailed modeling of photovoltaic module using MATLAB. NRIAG J. Astron. Geophys. 2014, 3, 53-61. [CrossRef]

47. Yoo, C.H.; Chung, I.Y.; Yoo, H.J.; Hong, S.S. A Grid Voltage Measurement Method for Wind Power Systems during Grid Fault Conditions. Energies 2014, 7, 7732-7745. [CrossRef]

48. Ackermann, T. Wind Power in Power Systems; John Wiley \& Sons: Chichester, UK, 2005.

49. Kim, S.H.; Oh, S.J.; Chung, I.Y.; Lee, H.J.; Chae, W.K. Voltage and Frequency Control Methods for Stand-alone Microgrids with Battery Storage Systems and Diesel Generators. In Proceedings of the 20th International Conference on Electrical Engineering, Jeju, Korea, 15-19 June 2014.

50. Kundur, P. Power System Stability and Control; McGraw-Hill: New York, NY, USA, 1994.

51. Kim, D.; Joung, K.W.; Choi, D.H.; Yoo, J.I.; Park, J.W.; Lee, H.J.; Baek, S.M.; Lee, S.H.; Lee, H.J.; Sim, J.B. Analysis on voltage and frequency responses of isolated microgrid according to minimisation of diesel generations. In Proceedings of the 24th International Conference \& Exhibition on Electricity Distribution (CIRED), Glasgow, UK, 12-15 June 2017.

52. Vink, K.; Ankyu, E.; Koyama, M. Multiyear microgrid data from a research building in Tsukuba, Japan. Sci. Data 2019, 6, 190020. [CrossRef] [PubMed]

53. Farret, F.A.; Simoes, M.G. Integration of Alternative Sources of Energy; John Wiley \& Sons: Hoboken, NJ, USA, 2006.

54. Blodgett, C.; Dauenhauer, P.; Louie, H.; Kickham, L. Accuracy of energy-use surveys in predicting rural mini-grid user consumption. Energy Sustain. Dev. 2017, 41, 88-105. [CrossRef]

55. Hartvigsson, E.; Ahlgren, E.O. Comparison of load profiles in a mini-grid: Assessment of performance metrics using measured and interview-based data. Energy Sustain. Dev. 2018, 43, 186-195. [CrossRef]

56. Jones, R.V.; Fuertes, A.; Lomas, K.J. The socio-economic, dwelling and appliance related factors affecting electricity consumption in domestic buildings. Renew. Sustain. Energy Rev. 2015, 43, 901-917. [CrossRef]

57. The Power Project. Available online: https:/ / power.larc.nasa.gov / (accessed on 10 October 2020).

58. IRENA. Renewable Power Generation Costs in 2017; IRENA: Abu Dhabi, UAE, 2018.

59. IRENA. Electricity Storage and Renewables: Costs and Markets to 2030; IRENA: Abu Dhabi, UAE, 2017. 